ARTICLE

https://doi.org/10.1038/s41467-020-15875-9

\title{
Stability and nuclear localization of yeast telomerase depend on protein components of RNase P/MRP
}

\author{
P. Daniela Garcia', Robert W. Leach (1) 2, Gable M. Wadsworth ${ }^{3}$, Krishna Choudhary ${ }^{4,5}$, Hua Li ${ }^{4}$, \\ Sharon Aviran (1) 4 , Harold D. Kim (10 ${ }^{3} \&$ Virginia A. Zakian ${ }^{1 凶}$
}

RNase $\mathrm{P}$ and MRP are highly conserved, multi-protein/RNA complexes with essential roles in processing ribosomal and tRNAs. Three proteins found in both complexes, Pop1, Pop6, and Pop7 are also telomerase-associated. Here, we determine how temperature sensitive POP1 and POP6 alleles affect yeast telomerase. At permissive temperatures, mutant Pop1/6 have little or no effect on cell growth, global protein levels, the abundance of Est1 and Est2 (telomerase proteins), and the processing of TLC1 (telomerase RNA). However, in pop mutants, TLC1 is more abundant, telomeres are short, and TLC1 accumulates in the cytoplasm. Although Est1/2 binding to TLC1 occurs at normal levels, Est1 (and hence Est3) binding is highly unstable. We propose that Pop-mediated stabilization of Est1 binding to TLC1 is a pre-requisite for formation and nuclear localization of the telomerase holoenzyme. Furthermore, Pop proteins affect TLC1 and the RNA subunits of RNase P/MRP in very different ways.

\footnotetext{
${ }^{1}$ Department of Molecular Biology, Princeton University, Princeton, NJ 08544, USA. ${ }^{2}$ Bioinformatics Group, Genomics Core Facility, Carl Icahn Laboratory, Princeton University, Princeton, New Jersey 08544, USA. ${ }^{3}$ School of Physics, Georgia Institute of Technology, Atlanta, Georgia 30332, USA. ${ }^{4}$ Department of Biomedical Engineering and Genome Center, University of California, Davis, California 95616, USA. ${ }^{5}$ Gladstone Institute of Data Science and Biotechnology,

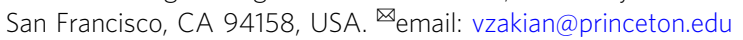


$\mathrm{T}$ elomerase is a ribonucleoprotein complex whose RNA component is the template for extending the G-rich strand of telomeric DNA. As in other organisms, Saccharomyces cerevisiae telomerase consists of both an RNA and multiple protein subunits (reviewed in ref. ${ }^{1}$ ). The RNA component, TLC1, is a large molecule ( 1200 nucleotides) with a complex secondary structure. Multiple proteins are TLC1-associated including the three Est proteins, Est1, Est2, and Est3, the heterodimeric Yku complex and the ring-shaped heptameric $\mathrm{Sm}\left(\mathrm{Sm}_{7}\right)$ complex (Fig. 1a). TLC1 and the three Est proteins are essential for telomerase action in vivo ${ }^{1}$. Est1 is the only telomerase subunit whose abundance and activity are cell cycle regulated, peaking in late S/ G2 phase $^{2-6}$. As in most organisms, yeast telomerase is not abundant: haploid cells contain $\sim 40-80$ molecules of the Est proteins $s^{4,7}$ and $\sim 30$ molecules of TLC1 ${ }^{8}$.

Biogenesis of TLC1 is complex as it undergoes several processing and intracellular trafficking events ${ }^{1}$ (Fig. 1b). TLC1 is transcribed by RNA polymerase II to make a $\sim 1300 \mathrm{nt}$ transcript ${ }^{9,10}$. The TLC1 transcript has a 7 -methyl-guanosine $(\mathrm{m} 7 \mathrm{G})$ cap at its $5^{\prime}$ end ${ }^{11}$. TLC1 can acquire a $3^{\prime}$ polyadenylated [poly(A)] tail, although the active form of TLC1 lacks poly(A) ${ }^{12}$. TLC1 then transits to the nucleolus where the $5^{\prime} \mathrm{m} 7 \mathrm{G}$ cap is hypermethylated ${ }^{11,13}$. Next TLC1 moves to the cytoplasm where the Est proteins bind ${ }^{13}$. Telomerase returns to the nucleus to elongate telomeres ${ }^{13,14}$ (Fig. 1b). If TLC1 is unable to exit the nucleus, as occurs when its export factors are missing, assembly of telomerase is blocked and telomere length is compromised ${ }^{15}$.

There are two pathways that recruit different forms of telomerase to the nucleus. Est2, the reverse transcriptase, binds the central core of TLC1 (Fig. 1a). The Yku heterodimer binds to a stem-loop region at the end of one of the structured arms of $\mathrm{TLC1}^{3,16}$. This TLC1-Yku interaction is required for TLC1-Est2 to enter the nucleus where it binds telomeric chromatin in G1 phase by its association with telomere-associated Sir4,13,16-18. However, this G1 telomerase is not competent to elongate telomeres as it lacks Est1 and Est3, and the complex is not associated with the G-tail ${ }^{19}$. Est1, which binds directly to both TLC1 and Est3 (Fig. 1a), has two important functions. Est1 is required for the second recruitment pathway, which occurs in late S/G2 phase $^{20}$ via a direct interaction between Est 1 and telomere-bound $\mathrm{Cdc1}^{2,7,21}$. Est1 also activates telomerase in late $\mathrm{S} / \mathrm{G} 2$ phase, perhaps by bringing Est3 to telomeres ${ }^{2-4,18}$. Although the Est1 activation step is essential for telomerase action, either recruitment pathway is sufficient to maintain stable (albeit short) telomeres ${ }^{18}$.

Mutations in $\sim 400$ genes affect telomere length, although in many cases, the mechanism by which they do so is unknown. To identify previously unknown regulators of telomerase, we carried out mass spectrometry (MS) to identify proteins that are telomerase-associated in vivo ${ }^{5}$. Using this method, we identified 115 high confidence telomerase-bound proteins. About 35\% of the telomerase-associated proteins function in RNA biogenesis, including Pop1, Pop6, and Pop7. The three Pop proteins were equally telomerase-associated in G1 and late S/G2 phase, suggesting that they are associated with telomerase throughout the cell cycle. Our demonstration that the three Pop proteins associate with telomerase ${ }^{5}$ was confirmed by a subsequent MS study ${ }^{22}$.

Pop 1, 6 and 7 are components of the highly conserved RNase P and RNase MRP multi-protein-RNA complexes ${ }^{23}$. The RNase P complex processes tRNAs by cleaving a $5^{\prime}$ precursor to produce mature tRNA. RNase MRP processes mitochondrial RNA, the 35s rRNA precursor, and mitotic cyclin B2 mRNA. Although most of the proteins that make up RNase P/MRP are found in both complexes, each complex contains a different RNA. The RNA subunits of RNase P and RNase MRP are, respectively, the $369 \mathrm{nt}$ RPR1 and the 340 nt NME1. The genes encoding the two RNAs and all of the protein subunits of RNase P/MRP are essential. The Pop proteins are thought to promote the proper folding of RPR1 and NME1 and to mediate substrate recognition by the two complexes $^{23}$. Of the eleven proteins in RNase P/MRP, only three are telomerase-associated with high confidence 5 . Pop proteins are found in the three cellular compartments through which TLC1 transits: nucleoplasm, nucleolus, and cytoplasm ${ }^{23}$. Therefore, Pop proteins could associate with telomerase at any (or all) of these locations.

Like TLC1, RPR1 and NME1 are highly structured RNAs. The Pop6/Pop7 heterodimer binds a stem-loop region called the P3 domain in RPR1 and NME1, which then stabilizes the subsequent binding of Pop1 to the P3 region ${ }^{23,24}$. Pop1 is thought to affect the global folding of RPR1 and NME1 in part by recruiting other proteins to the complex ${ }^{24}$. TLC1 also has a P3-like region, the CS2a/TeSS domain, that is also bound by Pop6/Pop722 (Fig. 1a). Remarkably, the P3 regions of NME1, RPR1, and TLC1 are functionally interchangeable ${ }^{22,25}$. Although the Est1 and Pop binding sites are separable (Fig. 1a), deletion of the CS2a/TeSS domain was reported to prevent Est1 binding to the mutant $\mathrm{TLC}^{22}$. Addition of Pop1 enhances telomerase activity in vitro. However, the mechanism by which Pop proteins affect telomerase in vivo is not known nor is it known if Pop proteins affect telomerase abundance or telomere length.

Here, we used an in vivo approach to determine how Pop1 and Pop6 affect telomerase and telomeres using pop temperaturesensitive alleles. At the permissive temperature of $24^{\circ} \mathrm{C}$, $p o p$ cells grow normally and have near wild type (WT) levels of protein, including Est1 and Est2. However, telomeres are 30\% shorter in Pop deficient cells, and telomerase binding to telomeres is low. The pop cells have twice as much TLC1 compared to WT cells, while NME1 levels are decreased. The global secondary structure of NME1, but not TLC1, is perturbed in pop mutants. Thus, even though Pop1 and 6 bind to similar structures in TLC1 and NME $1^{22}$, they affect the two RNAs in opposite ways. In contrast to an earlier study ${ }^{22}$, DMS protection showed that levels of Est1 and Est2 binding to TLC1 are normal in pop cells. However, this binding is highly unstable. Moreover, TLC1 accumulates in the cytoplasm in pop cells, even though pop cells have normal levels of Est proteins and TLC1 export factors. We propose that Pop1, 6, and 7 stabilize the cytoplasmic association of Est1 (and to a lesser extent Est2) with TLC1, and the failure to do so prevents formation of a stable holoenzyme, which traps TLC1 in the cytoplasm.

\section{Results}

Strains to study effects of reduced Pop proteins. The goal of this paper is to determine the functional significance of the association of Pop proteins with telomerase. This goal is complicated by the fact that all of the subunits of RNase P/MRP are essential to process tRNAs and ribosomal RNAs. Therefore, the absence of any one subunit ultimately stops protein synthesis. Direct effects of Pop proteins on telomerase must be distinguished from their effects on protein synthesis.

Experiments were carried out using temperature sensitive $p o p$ strains and their isogenic WT controls ${ }^{26}$. Although the pop strains were known to be temperature sensitive, they were otherwise uncharacterized. While some experiments were conducted in pop7-PH cells, the short telomere phenotype in this strain was not completely suppressed by introducing a plasmidborne $P O P 7$ gene. Therefore, we report only experiments carried out in pop1-500 and pop6-502 (hereafter, pop1 and pop6) cells. Sequencing the mutant pop1 revealed that it had seven amino acid changes spread throughout the 875 amino acid protein (Fig. 2a). POP6 encodes a 158 amino acid protein. The mutant 
a

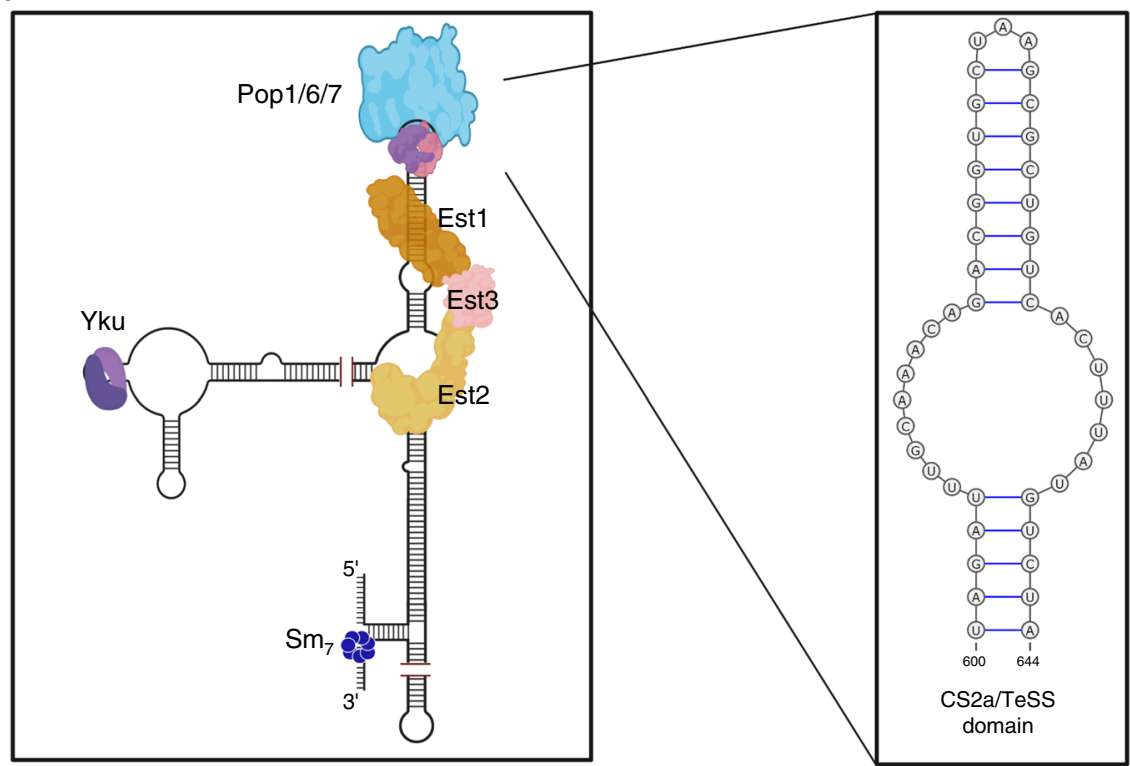

b

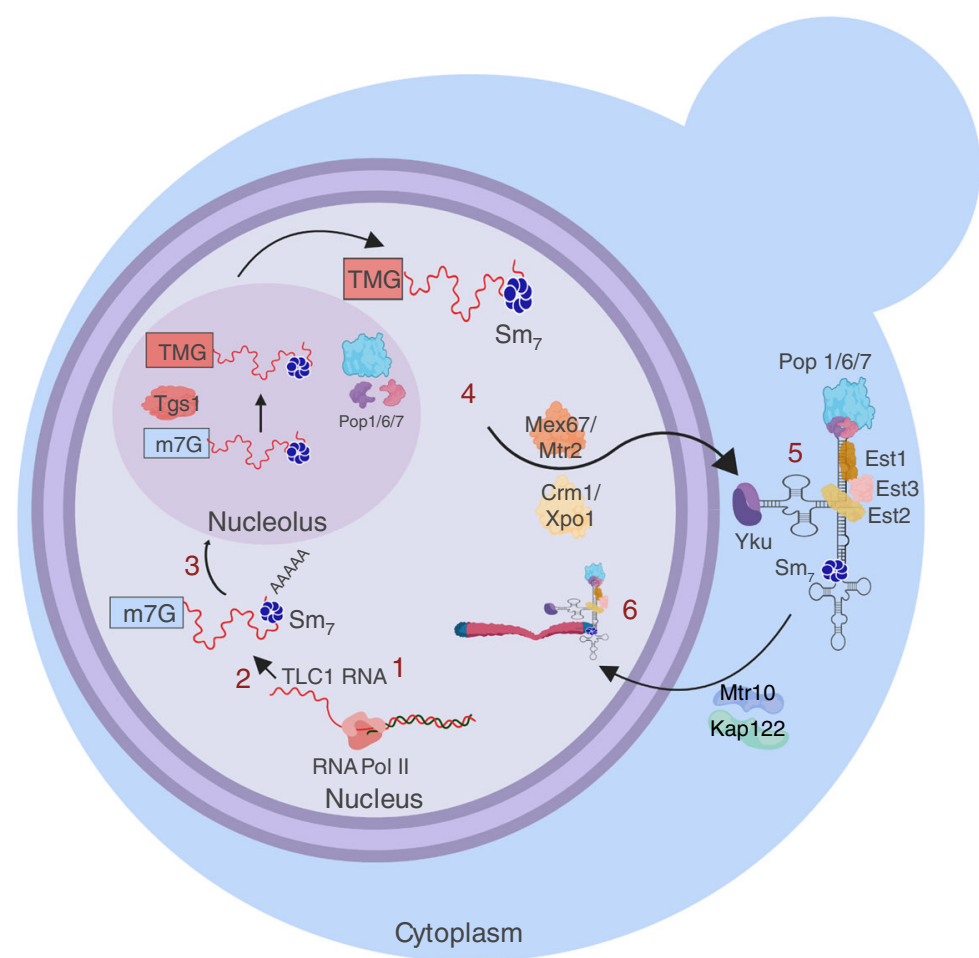

Fig. 1 Structure and biogenesis of TLC1. a Est1 and Pop proteins bind at separable sites near the end of the Est1 arm of TLC1. Est3 interacts directly with Est1 and Est2, possibly bridging the two, and both of these associations are required for Est 3 to bind telomeres. Est2 binds the central core of TLC1. (The proteins and RNA are not drawn to scale; $1 \mathrm{a}$ is a static representation meant to illustrate the sites on TLC1 to which the indicated proteins bind and the protein-protein interactions amongst the telomerase subunits.) The binding sites for the heterodimeric Ku complex and the Sm7 complex are also shown. Insert shows magnified view of the CS2a/TeSS domain to which a Pop6/7 heterodimer binds and then recruits Pop1 ${ }^{22}$. b Biogenesis of TLC1: (1) TLC1 is transcribed in the nucleus by RNA polymerase II. (2) The newly transcribed TLC1 has a 5'-7 methylguanosine cap, is bound by the Sm7 complex which helps stabilize the RNA ${ }^{11}$ and a fraction of molecules have a poly(A) 3'tail. (3) TLC1 transits to the nucleolus where the $5^{\prime}$ cap gets hypermethylated by the Tgs1 methyltransferase. (4) TLC1 is bound by the indicated export factors that bring it to the cytoplasm. (5) TLC1 lacking a poly(A) tail assembles with the Est proteins in the cytoplasm. (6) In G1 phase, when Est1 abundance is low, Est1 and Est3 are not TLC1-associated. However, a Yku-TLC1-Est2 complex forms and is telomere associated in G1 phase. In late S/G2 phase, the holoenzyme forms in the cytoplasm and binds import factors Mtr10/Kap122 that mediate holoenzyme entry into the nucleus. The holoenzyme binds and elongates telomeres. Pop proteins are present in the nucleoplasm, nucleolus, and cytoplasm. The compartment in which Pop proteins bind TLC1 is not known. However, Pop proteins are TLC1-associated in both G1 and G2/M phase (see text for references). Images were made in BioRender (biorender.com). 
a

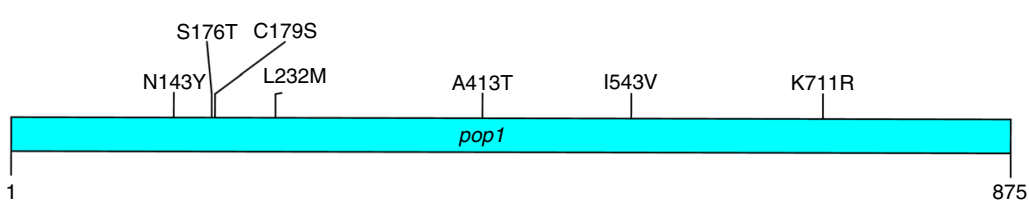

b

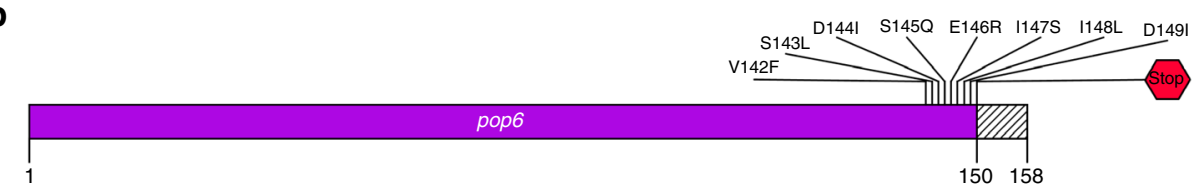

C

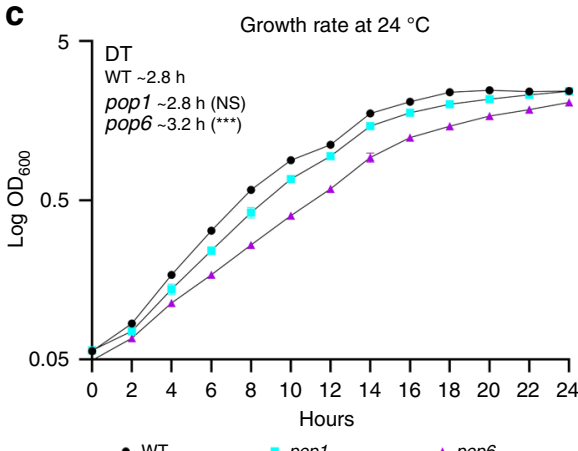

e

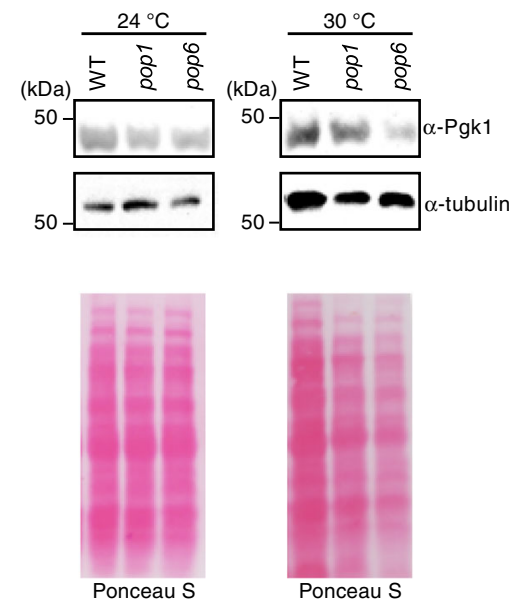

d
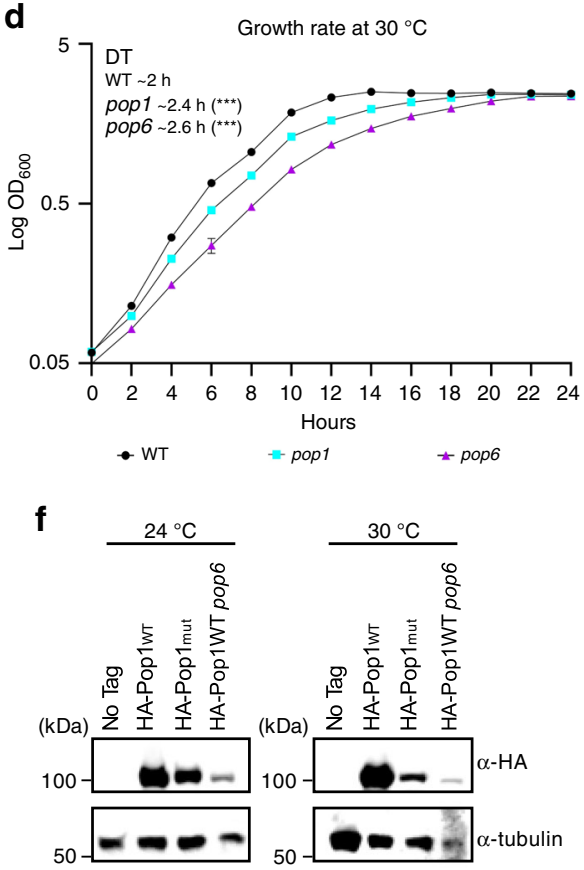

g

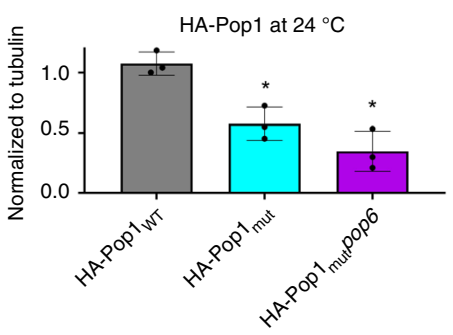

Fig. 2 Growth and global protein levels are similar in pop and WT cells at $24^{\circ} \mathbf{C}$. Diagrams of the proteins encoded by the pop alleles used herein. Silent mutations are not shown. $\mathbf{a}$ The positions of the seven amino acid substitutions in the 875 amino acid protein encoded by the pop1 allele (blue) are shown. The nucleotide mutations that led to these substitutions are: $225 \mathrm{G} \rightarrow \mathrm{A}, 427 \mathrm{~A} \rightarrow \mathrm{T}, 526 \mathrm{~T} \rightarrow \mathrm{A}, 535 \mathrm{~T} \rightarrow \mathrm{A}, 695 \mathrm{~A} \rightarrow \mathrm{T}, 792 \mathrm{~T} \rightarrow \mathrm{C}, 1237 \mathrm{G} \rightarrow \mathrm{A}, 1627 \mathrm{~A} \rightarrow$ $\mathrm{G}, 2132 \mathrm{~A} \rightarrow \mathrm{G}$ (numbers are positions of altered nucleotides). b Diagram of the protein produced by the pop6 allele (purple), which contains a deletion at nucleotide 421 resulting in an eight amino acid substitution (amino acids 142-149) and loss of the nine terminal aminoacids (dashed lines from 150-158) due to a stop codon at position 150. Growth rates of pop1 and pop 6 cells at $\mathbf{c} 24^{\circ} \mathrm{C}$ and $\mathbf{d} 30^{\circ} \mathrm{C}$. e Pgk1 and tubulin proteins from WT, pop1 or pop6 cells grown for $\sim 50$ generations were analyzed by western blotting. Although in this western, there appears to be more Pgk1 in WT than in pop cells at $24{ }^{\circ} \mathrm{C}$, using a two-tailed Student's $t$-test, the differences were not significant. Total protein was stained with Ponceau S. $\mathbf{f}$ Western blots of proteins from a no tag

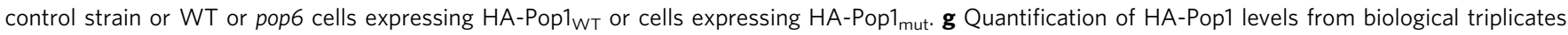
(black circles) of WT (gray bar), pop1 (blue bar) and pop6 (purple bar) grown at $24{ }^{\circ} \mathrm{C}$ were normalized to tubulin and WT protein levels. (Because, epitope tagged mutant Pop6 did not support viability, the effects of temperature on Pop6 were not studied). Error bars are one standard deviation from the average value of three or more independent experiments. $P$-values were calculated using unpaired two-tailed Student's $t$-test; ${ }^{\star} P \leq 0.05,{ }^{\star \star} P \leq 0.01,{ }^{\star \star \star} P \leq 0.001$, ${ }^{\star \star \star \star} P \leq 0.0001$; NS, not significant, $P>0.05$. Source data are provided as a Source Data file.

pop6 allele had a single nucleotide deletion near the end of the open reading frame. This deletion changed the sequence of 8 amino acids, as well as introducing a stop codon that resulted in a nine amino acid truncation (Fig. 2b).
To establish the appropriate conditions for experiments, we determined the growth rates of $p o p$ mutants at different temperatures. At $24^{\circ} \mathrm{C}$, pop 1 and pop 6 cells had doubling times similar to that of WT in both liquid and solid media (Fig. 2c; 
Supplementary Fig. 1). At $30^{\circ} \mathrm{C}$, pop1 and pop6 cells grew indefinitely, but their growth rates were significantly slower than WT (Fig. 2d; Supplementary Fig. 1). At $37^{\circ} \mathrm{C}$, both mutants divided only a few times. Thus, $24^{\circ} \mathrm{C}, 30^{\circ} \mathrm{C}$ and $37^{\circ} \mathrm{C}$ are, respectively, permissive, semi-permissive, and non-permissive temperatures for pop1 and pop6 cells.

Global protein levels were similar in pop1, pop6 and WT cells at $24^{\circ} \mathrm{C}$, but were detectably lower at $30^{\circ} \mathrm{C}$ (Fig. 2e). By western blot, alpha tubulin and Pgk1 protein levels were similar to WT at $24^{\circ} \mathrm{C}$ but only $0.5 \times \mathrm{WT}$ at $30^{\circ} \mathrm{C}$ (Fig. 2e). Levels of mutant Pop1 (HA-Pop $\left.1_{\text {mut }}\right)$ were reduced even at $24^{\circ} \mathrm{C}(0.6 \times$ WT Pop 1$)$. In addition, at $24^{\circ} \mathrm{C}, \mathrm{HA}-\mathrm{Pop} 1_{\mathrm{WT}}$ was less abundant in pop 6 than in WT cells $(0.3 \times$ WT levels; Fig. $2 \mathrm{f}, \mathrm{g})$. Therefore, the abundance of some (and perhaps most) proteins was largely unaffected in $p o p$

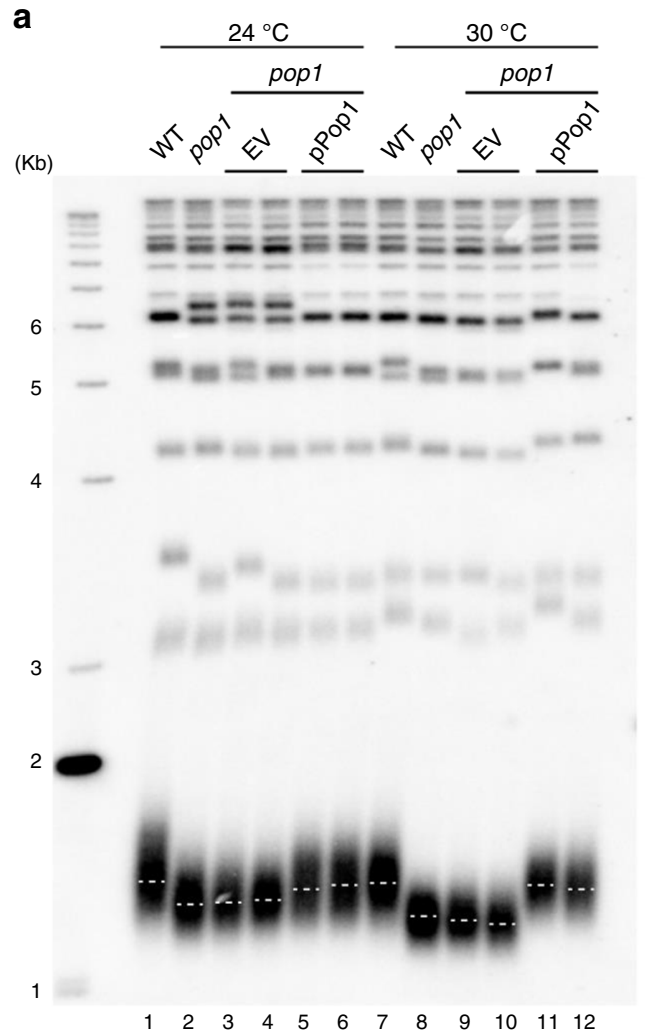

cells at $24^{\circ} \mathrm{C}$. However, mutant Pop1 and probably Pop6 were unstable even at permissive temperatures. Based on these results, all experiments were carried out at $24^{\circ} \mathrm{C}$ as growth rates and bulk protein levels were similar to WT, but Pop1 (and probably Pop6) levels were reduced. Many experiments were also conducted at $30{ }^{\circ} \mathrm{C}$. We reasoned that a phenotype that was detected at permissive temperature $\left(24^{\circ} \mathrm{C}\right)$ and worsened at semi-permissive temperature $\left(30^{\circ} \mathrm{C}\right)$ was likely a direct effect of Pop proteins on telomerase.

pop mutants have shorter telomeres than WT cells. To determine if Pop proteins are needed for WT telomere length, telomeres were measured by Southern blot analysis (Fig. 3). The

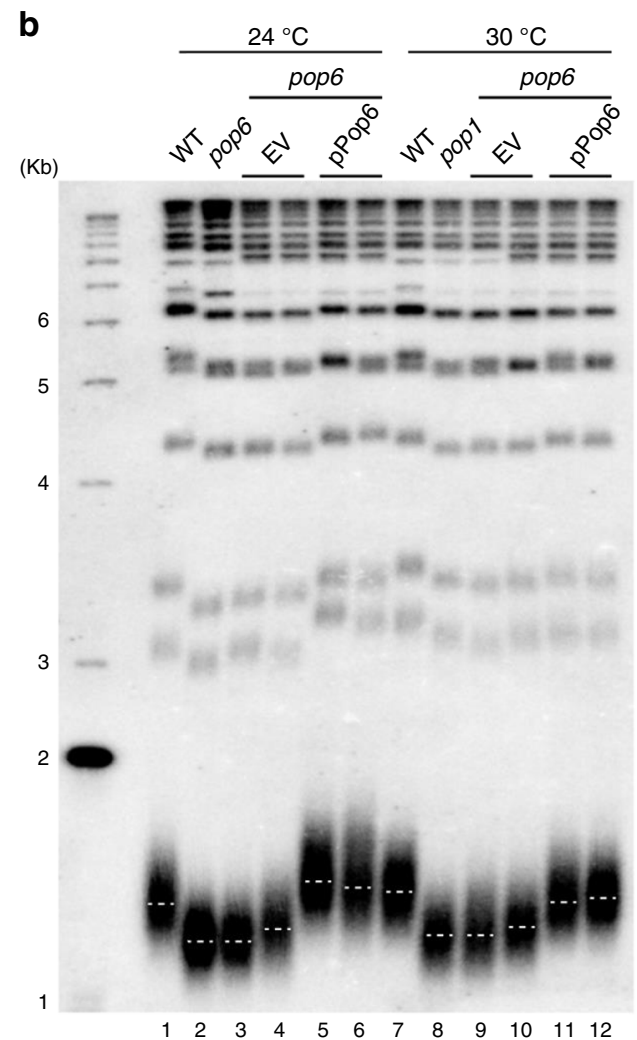

\begin{tabular}{|c|c|c|}
\hline Ctrain & Telomere length (bp) at $24^{\circ} \mathrm{C}$ & Telomere length (bp) at $30^{\circ} \mathrm{C}$ \\
\hline $\mathrm{WT}$ & $385 \pm 9$ & $401 \pm 8$ \\
\hline pop1 & $281 \pm 3^{* * *}$ & $274 \pm 24^{* * *}$ \\
\hline pop1+ EV & $294 \pm 15^{* *}$ & $288 \pm 17^{* * *}$ \\
\hline pop1+pPOP1 & $413 \pm 18 \mathrm{NS}$ & $363 \pm 27^{*}$ \\
\hline pop6 & $216 \pm 4^{* * *}$ & $195 \pm 23^{* * *}$ \\
\hline pop6 + EV & $224 \pm 18^{* * *}$ & $202 \pm 17^{* *}$ \\
\hline pop6 + pPOP6 & $405 \pm 11 \mathrm{NS}$ & $387 \pm 21 \mathrm{NS}$ \\
\hline
\end{tabular}

Fig. 3 pop1 and pop6 cells have short telomeres at 24 and $30^{\circ} \mathrm{C}$ that is reversed by introducing a WT copy of POP1 or POP6. DNA was isolated from the indicated strains, digested with Xhol, and analyzed by Southern blotting using a radio-labeled $\mathrm{TG}_{1-3}$ probe. Cells were grown at 24 or $30{ }^{\circ} \mathrm{C}$ for $\sim 75$ generations prior to DNA extraction. $\mathbf{a}, \mathbf{b}$ EV, empty vector; $\mathrm{pPOP1}$ or $\mathrm{pPOP6}$, the same vector containing POP1 or POP6. Dotted white lines mark the average telomere length in each sample. c Quantitation of telomere lengths in at least three biological isolates of each strain. Size of telomeric tracts were determined by subtracting 875 nts of $Y^{\prime}$ DNA from the sizes of the terminal Xhol fragments. Introducing a WT copy of the POP gene reversed telomere shortening in pop1 and pop6 cells. P-values were calculated using unpaired two-tailed Student's $t$-test; ${ }^{\star} P \leq 0.05,{ }^{\star \star} P \leq 0.01,{ }^{\star \star \star} P \leq 0.001,{ }^{\star \star \star \star} P \leq 0.0001$; NS, not significant, $P>0.05$. Asterisks indicate significance of telomere length differences in pop cells versus WT. 
a

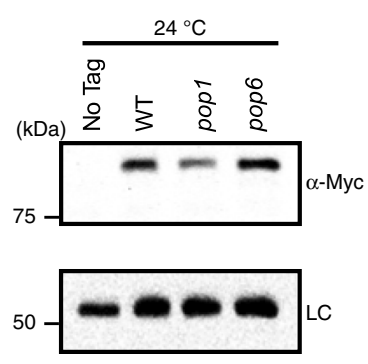

c

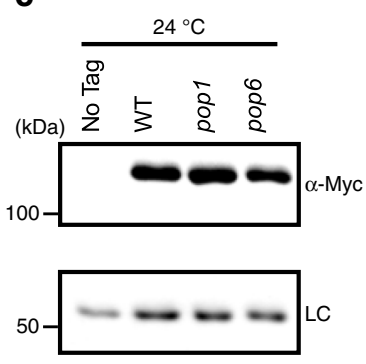

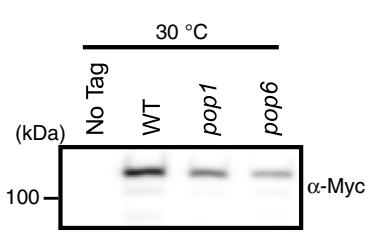

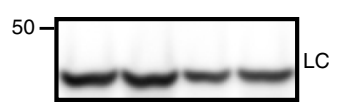

b

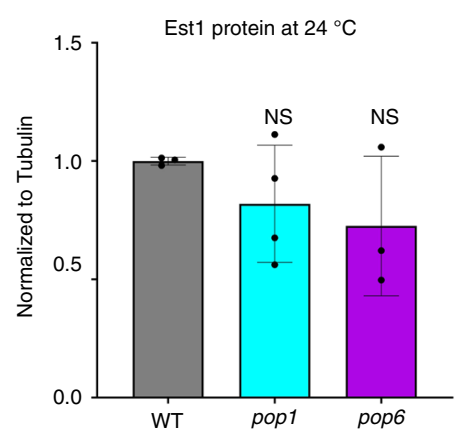

d

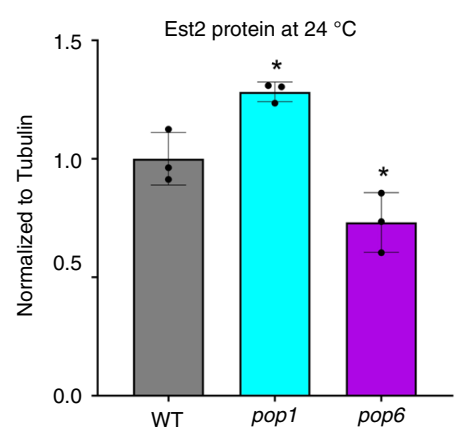

e

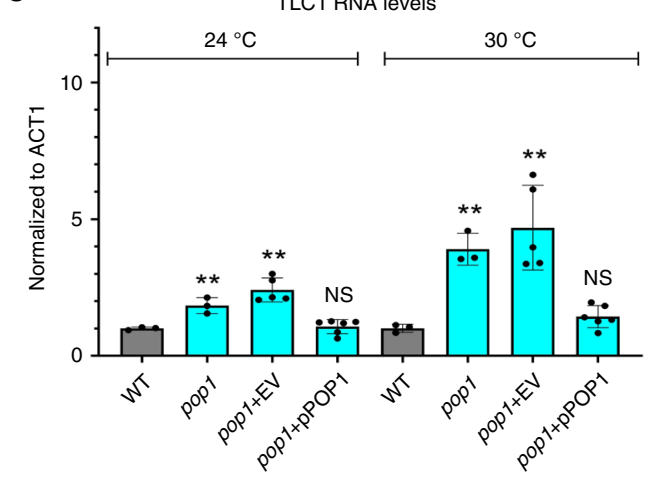

f

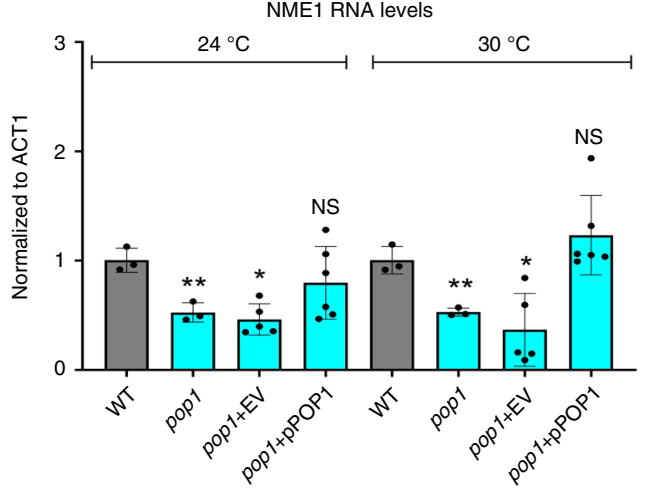

average telomere length in isogenic WT cells was 385 base pairs (bp) at $24^{\circ} \mathrm{C}$ and $400 \mathrm{bp}$ at $30^{\circ} \mathrm{C}$. At $24^{\circ} \mathrm{C}$, telomeres in pop 1 and pop6 cells were short $\left(\sim 0.7 \times \mathrm{WT} ; P<10^{-3}\right.$, unless otherwise noted, unpaired two-tailed Student's $t$-tests were used to determine statistical significance; see Fig. $3 \mathrm{c}$ for more detail). The extent of shortening was even greater at $30^{\circ} \mathrm{C}(0.6$ and $0.5 \times \mathrm{WT}$; Fig. 3a, b). The short telomere phenotype was reversed by introducing a plasmid-borne copy of POP1 or POP6. Unlike telomerase deficient cells, the length of pop telomeres was stable, and cells did not senesce. Because telomere shortening was
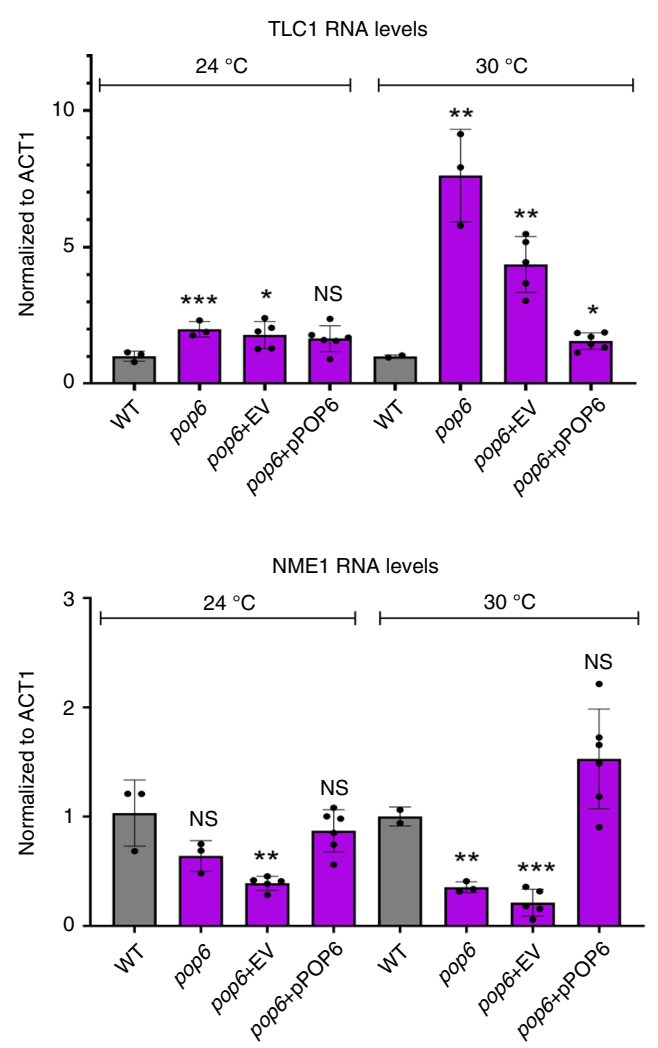

evident at $24^{\circ} \mathrm{C}$ when growth rates and protein levels were similar in WT and mutant cells, it was likely due to reduced abundance and/or function of Pop1 and/or Pop6. We conclude that Pop1 and Pop6 are required for WT telomere length.

Short telomeres in pop cells are not due to low Est1 or 2. To determine if the abundance of key telomerase subunits are Pop protein-dependent, we did western blots on WT and pop cells expressing epitope tagged Est 1 or Est2 (Fig. $4 \mathrm{a}-\mathrm{d}$ ). At $24^{\circ} \mathrm{C}$, Est1 
Fig. 4 At $24^{\circ} \mathbf{C}$, TLC1 levels are higher in pop cells, while Est1 and Est2 levels are similar to WT. Protein extracts from the indicated strains grown at $24^{\circ}$ or $30^{\circ} \mathrm{C}$ were analyzed by western blotting using a MYC-antibody to detect a Est1-MYC or $\mathbf{c}$ Est2-MYC. [(Est3 levels were not determined because we do not have an epitope tagged allele of Est3 that has WT telomere length and that can be detected by westerns in whole cell extracts ${ }^{4}$ ]. Levels of $\mathbf{b}$ Est1-MYC and $\mathbf{d}$ Est2-MYC from three biological replicates (black circles) grown at $24^{\circ} \mathrm{C}$ were quantified after being normalized to levels of tubulin in the same samples. The normalized value of each protein in WT cells was defined as one. At $30^{\circ} \mathrm{C}$, levels of Est1-MYC and Est2-MYC in pop cells were normalized only to WT levels of Est1 or Est2 as tubulin and Pgk1 levels were also lower at $30^{\circ} \mathrm{C}$. The fold difference in Est1-MYC or Est2-MYC in pop1 and pop6 cells compared to WT is shown. The loading control (LC) for the Est1-MYC western at $30^{\circ} \mathrm{C}$ was Pgk1. For all other westerns, the LC was tubulin. e Total RNA was extracted from cells grown at $24^{\circ} \mathrm{C}$ or $30^{\circ} \mathrm{C}$ for $\sim 50$ generations. RNA levels were determined by RT-qPCR for e TLC1 or f NME1 in WT (gray bars), pop1 (blue bars) and pop6 (purple bars). Individual biological replicates are shown (black circles). TLC1 and NME1 levels were normalized to levels of ACT1 mRNA in the same samples using the $2^{-\Delta \Delta \mathrm{Ct}}$ method ${ }^{56}$. At both 24 and $30^{\circ} \mathrm{C}$, the increase in $\mathrm{TLC1}$ (and the decrease in NME1) RNA in pop cells was suppressed by a WT copy of the mutated POP gene. Error bars are one standard deviation from the average value of three or more independent experiments. $P$-values were calculated using unpaired two-tailed Student's $t$-test; ${ }^{\star} P \leq 0.05,{ }^{\star \star} P \leq 0.01,{ }^{\star \star \star} P \leq 0.001,{ }^{\star \star \star \star} P \leq 0.0001$; NS, not significant, $P>0.05$. Source data are provided as a Source Data file.

levels were not significantly different from WT in both pop strains $(P=0.19)$ (Fig. 4a, b). Compared to WT levels, Est2 abundance was modestly increased in pop1 $(1.3 \times \mathrm{WT}, P=0.01)$ and decreased in pop6 cells $\left(0.7 \times\right.$ WT, $P=0.05$; Fig. 4 c, d). At $30^{\circ} \mathrm{C}$, Est 1 and Est 2 levels in both pop strains were $\sim 0.3 \times$ and $\sim 0.6 \times \mathrm{WT}$ levels, respectively (the reduction in Est2 levels was significant only in pop 1 cells; Fig. $4 \mathrm{~b}, \mathrm{~d})$. The abundance of the loading control was similarly reduced $(\sim 0.5 \times \mathrm{WT}$; Fig. $4 \mathrm{a}, \mathrm{c})$. As there were no significant trends in Est1 or Est2 levels that correlate with short telomeres, we conclude that short telomeres in $24^{\circ} \mathrm{C}$ grown pop cells are not explained by reduced Est1 or Est 2 .

TLC1 levels are high and NME1 levels are low in pop cells. Pop proteins bind directly to their RNA targets: TLC1, NME1 and RPR1 22,27 . NME1 and RPR1 are less abundant in Pop-deficient cells $^{28}$. To determine if TLC1 levels were similarly reduced, we used reverse transcriptase quantitative PCR (RT-qPCR) (Fig. 4e). At $24^{\circ} \mathrm{C}$, TLC1 levels were $2 \times$ higher in both pop strains $(P<$ $0.05)$. This increase was even higher at $30^{\circ} \mathrm{C}(4-8 \times \mathrm{WT} ; P<0.01$; Fig. 4e). In contrast, at $24^{\circ} \mathrm{C}, \mathrm{NME} 1$ was lower in both pop strains $(\sim 0.4-0.7 \times$ WT; $P<0.03$; Fig. 4 f). NME1 levels were even lower in $30{ }^{\circ} \mathrm{C}$ grown pop cells $(\sim 0.25 \times \mathrm{WT} ; P<0.001)$. Thus, the short telomere phenotypes of pop1 and pop6 cells are not due to reduced TLC1. Unexpectedly, Pop proteins have different effects on NME1 and TLC1, even though they bind to regions with similar sequence and structure in the two RNAs ${ }^{22}$.

Short telomeres in pop cells are not due to titration of $\mathbf{Y k u}$. The Yku heterodimer not only binds TLC1, it also binds telomeres independently of its association with $\mathrm{TLC1}^{3}$. This binding protects telomeres from nucleolytic degradation in G1 phase ${ }^{29,30}$. When TLC1 is expressed at very high levels, it titrates Yku from telomeres, resulting in telomere shortening ${ }^{16}$. These results raised the possibility that the short telomeres in pop cells might be explained by removal of Yku from telomeres due to increased TLC1 (Supplementary Fig. 2). If pop mutants and Yku depletion affect telomere length by the same mechanism, telomeres should be similarly short in double versus single mutants. However, double mutants ( $p o p 1$ or pop6 yku70 cells) had even shorter telomeres compared to any of the single mutants $(P<0.001$; Supplementary Fig. 2). Thus, the short telomere phenotypes of pop mutants are not due to loss of Yku from telomeres.

Trimethylated TLC1 levels are similar in pop and WT cells. The 2,2,7 trimethylation (TMG) of the TLC1 $5^{\prime}$ methylguanosine $(\mathrm{m} 7 \mathrm{G})$ cap is catalyzed in the nucleolus by the Tgs1 methyltransferase ${ }^{31}$. Acquisition of the TMG is probably required for exit from the nucleolus, because TLC1 accumulates there in $\operatorname{tgs} 1 \Delta$ cells $^{13}$. To monitor the efficiency of trimethylation, we immuno- precipitated TLC1 with an anti-TMG antibody (Millipore). The amount of TLC1 precipitated was not significantly different in pop1 or pop6 versus WT cells at $24^{\circ} \mathrm{C}$ (pop1 $P=0.15$; pop6 $P=$ 0.5 ) or $30^{\circ} \mathrm{C}$ (Fig. 5; pop1 $P=0.3$; pop6 $P=0.6$ ). We conclude that Pop proteins do not affect acquisition of the TMG cap.

Sequence of $3^{\prime}$ ends of TLC1 is not altered in pop cells. RNase $\mathrm{P} / \mathrm{MRP}$ use their endonuclease activities to process RNA substrates. Therefore, we determined if the processing of TLC1 was altered in pop mutants. TLC1 exists in two forms, a long poly(A) form $(\sim 1300 \mathrm{nts})$ that accounts for a small fraction of the total TLC1 and a shorter poly(A) minus form $(\sim 1157 \mathrm{nt})$ that also lacks $\sim 140$ nucleotides from the $3^{\prime}$ end of the long form. The short form, which accounts for most of the TLC1, purifies with active telomerase $\mathrm{e}^{12}$. There is no known function for the poly $(\mathrm{A})$ form ${ }^{32}$.

There are two models to explain the occurrence of poly(A) TLC1. The first model suggests that mature TLC1 is generated by cleavage of the poly $(\mathrm{A})$ isoform ${ }^{10}$. The second model proposes that the $3^{\prime}$ end of the mature TLC1 is generated by a poly(A)independent transcription termination pathway ${ }^{32,33}$. According to this model, poly (A) TLC1 is a dead-end product generated when termination fails ${ }^{1,32}$. Given that the RNase P/MRP complexes process other RNAs, the first model provides a potentially unifying hypothesis for the effects of Pop proteins on its RNA targets. The hypothesis that Pop proteins are needed to generate active TLC1 from the longer poly(A) form predicts that the fraction of TLC1 in the long form will be higher in $24^{\circ} \mathrm{C}$ grown pop cells and even higher at $30^{\circ} \mathrm{C}$.

To determine if Pop proteins affect poly(A) addition, we determined the fraction of TLC1 in the two isoforms in pop and WT cells by both northern analysis (data not shown) and $3^{\prime}$ RACE (Rapid amplification of cDNA ends). Contrary to the first hypothesis, the ratio of long to short forms of TLC1 was significantly lower in pop1 and pop6 cells than in WT cells at $24^{\circ}$ C (Fig. 6b; ratios of $\sim 0.80$, WT; $\sim 0.45$, pop cells; pop1 $P=0.01$; pop6 $P=0.03)$. The ratios were even lower in pop cells at $30^{\circ} \mathrm{C}$.

As a further test, we considered the possibility that impaired RNA processing in pop cells might alter the sequence of the $3^{\prime}$ ends of TLC1. We ruled out this possibility by sequencing the $3^{\prime}$ ends of all cDNAs shorter than $500 \mathrm{bps}$ (Fig. 6c, d). The distribution of lengths and sequences of the $3^{\prime}$ ends were not significantly different in pop versus WT cells at $24^{\circ} \mathrm{C}$. Combined with the TMG data, the $5^{\prime}$ and $3^{\prime}$ ends of TLC1 are processed normally in pop mutants.

The Est1-TLC1 association is unstable in pop cells at $24^{\circ} \mathrm{C}$. Est 1 and Est2 bind directly to telomerase RNA (Fig. 1a). By RNA immunoprecipitation (RNA-IP), Est1 and Est2 bind at reduced 
a

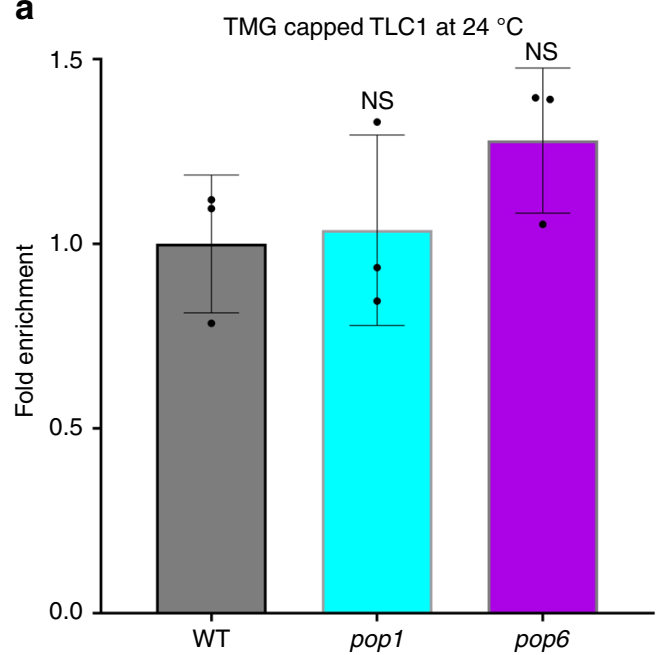

b

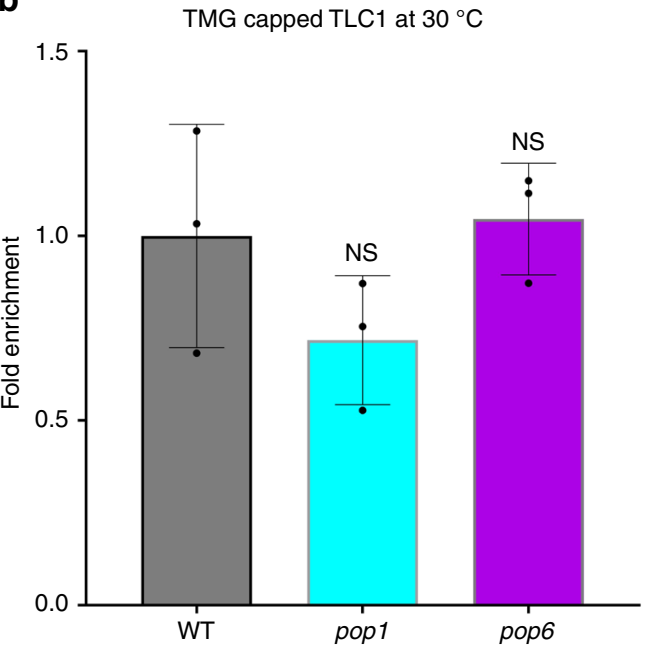

Fig. 5 Trimethylation of the TLC1 $\mathbf{5}^{\prime}$ cap is not affected in pop cells. Total RNA was extracted from WT (gray bars), pop1 (blue bars) and pop6 (purple bars) cells and TMG-capped TLC1 was immunoprecipitated using an anti-TMG antibody in cells grown at $24^{\circ} \mathrm{C}$ (a) or $30^{\circ} \mathrm{C}$ (b). TLC1 in the immunoprecipitate was measured by RT-qPCR. IP/INPUT TLC1 was normalized to IP/INPUT ACT1 mRNA. Bars are data from three independent biological isolates (black circles). Error bars are one standard deviation from the average value of three or more independent experiments. P-values were calculated using unpaired two-tailed Student's $t$-test; ${ }^{\star} P \leq 0.05,{ }^{\star \star} P \leq 0.01,{ }^{\star \star \star} P \leq 0.001,{ }^{\star \star \star \star} P \leq 0.0001$; NS, not significant, $P>0.05$. Source data are provided as a Source Data file.

levels to a deletion derivative of $\mathrm{TLC}^{22,25}$. This deletion derivative lacks the P3-like CS2a domain to which Pop proteins bind. To determine if the association of WT TLC1 with Est1 or Est2 occurred normally in pop cells at $24^{\circ} \mathrm{C}$, we immunoprecipitated Est1 or Est 2 from mutant and WT cells. We then did RT-qPCR on the immunoprecipitate (IP) to determine the fraction of TLC1 that was associated with Est1 or Est2. The amount of TLC1 in the Est1 IP was significantly lower than in WT cells $(\sim 0.14 \times$ WT in both pop strains; $P<5 \times 10^{-4}$; Fig. 7a). This dramatic decrease in Est1-TLC1 binding occurred even though Est1 abundance was similar in pop and WT cells (Fig. 4a). Est2 association with TLC1 was reduced significantly only in pop6 cells $(0.6 \times \mathrm{WT}, P=0.01$, Fig. 7b).

We also used RNA-IP to determine the level of TLC1 binding to HA-Pop $1_{\mathrm{WT}}$ in pop6 cells and HA-Pop $1_{\text {mut }}$ in pop1 cells (Supplementary Fig. 3). In $24^{\circ} \mathrm{C}$ grown cells, TLC1 binding to HA-Pop $1_{\text {mut }}$ was only $0.15 \times$ of its binding to WT Pop $1(P=$ $0.030)$. At the same temperature, TLC1 binding to WT Pop1 in pop6 cells was even lower $(0.05 \times P O P 6$ cells; $P=0.007)$. Reduced TLC1 binding to Pop1 can be explained by reduced levels of Pop1 in both strains (Fig. 2f, g). We conclude that mutant Pop1 reduces the stable association of Est1 to TLC1 (and in pop6 cells, Est2). In addition, in combination with the data on Pop1 abundance (Fig. 2f, g), Pop1 stability and its binding to TLC1 are both Pop6dependent.

Telomerase binding to telomeres is deficient in pop cells. Results from RNA-IP indicate that the telomerase holoenzyme was unstable in pop cells (Fig. 7a, b). This finding predicts that telomerase binding to telomeres would be low in these mutants. To test this hypothesis, chromatin immunoprecipitation (ChIP) was done in $24^{\circ} \mathrm{C}$ grown WT, pop1 and pop 6 cells expressing Est1 or Est2. We determined binding of both proteins to telomeres VI-R and XV-L (Fig. 7c, d). The binding of both Est1 $(\sim 0.3 \times \mathrm{WT}, P<$ $0.01)$ and Est $2(0.7 \times \mathrm{WT}, P<0.05)$ was significantly reduced at both telomeres in both strains. Impaired stability of the telomerase holoenzyme and its reduced telomere binding likely explain the short telomere phenotypes of pop 1 and pop6 cells at $24^{\circ} \mathrm{C}$.
TLC1 folding is WT in pop cells except at Pop binding site. RNA-IP (Fig. 7a, b) revealed that in $24^{\circ} \mathrm{C}$ grown pop cells, the level of TLC1 association with Est1 was only $\sim 14 \%$ of the level in WT cells. In vitro studies suggest that the secondary structures of NME1 and RPR1 are altered in the absence of Pop proteins ${ }^{24,34}$. Therefore, we considered the possibility that the structure of the Est1 and (to a lesser extent) the Est2 binding sites in TLC1 might be Pop protein dependent. This model was appealing as it could provide an explanation for reduced binding of Est proteins to TLC1 in pop cells. To test this possibility, we used DMS-MaPseq, a method for high throughput chemical probing of RNA structure in vivo 35,36 . In addition to TLC1, we determined the structure of NME1, which is expected to be Pop protein dependent, in the same RNA samples.

WT and pop cells were treated in vivo with (or without) dimethyl sulfate (DMS). DMS methylates unpaired adenosines and cytosines in $\mathrm{RNA}^{37}$. The methylation sites were detected using the reverse transcriptase TGIRT III, which introduces mutations, rather than stopping, at methylated sites ${ }^{38}$. The resulting cDNAs were amplified and sequenced by next generation sequencing. Because the 1157 nt TLC1 was too large to be sequenced as a single amplicon, it was divided into three parts. In total, we sequenced 180 libraries to monitor folding in $60 \%$ of the 1157 nt TLC1 and $75 \%$ of the 341 nt NME1. After pre-processing, there were an average of 680,000 reads per $A$ or C. This depth of coverage is sufficient to detect reproducible changes in structure-dependent methylation patterns, even if these changes occur in only a subpopulation of transcripts ${ }^{39-41}$.

To test if either TLC1 or NME1 RNAs were differentially reactive to DMS in pop versus WT cells, we first calculated the DMS reactivity at each nucleotide. Then, we used dStruct to determine regions with statistically significant differences in reactivities between $p o p$ and WT cells ${ }^{41}$. dStruct uses a dissimilarity score $(\Delta d)$ to assess variation in reactivities within biological replicates for each cell type ( $p o p$ or WT) and between pop and WT cells. It then screens for regions where the latter variation exceeds the former and evaluates the significance of such differences. Regions of five nucleotides (or more) that had qvalues $<0.1$ and $\Delta d>0.01$ were considered statistically significant. 

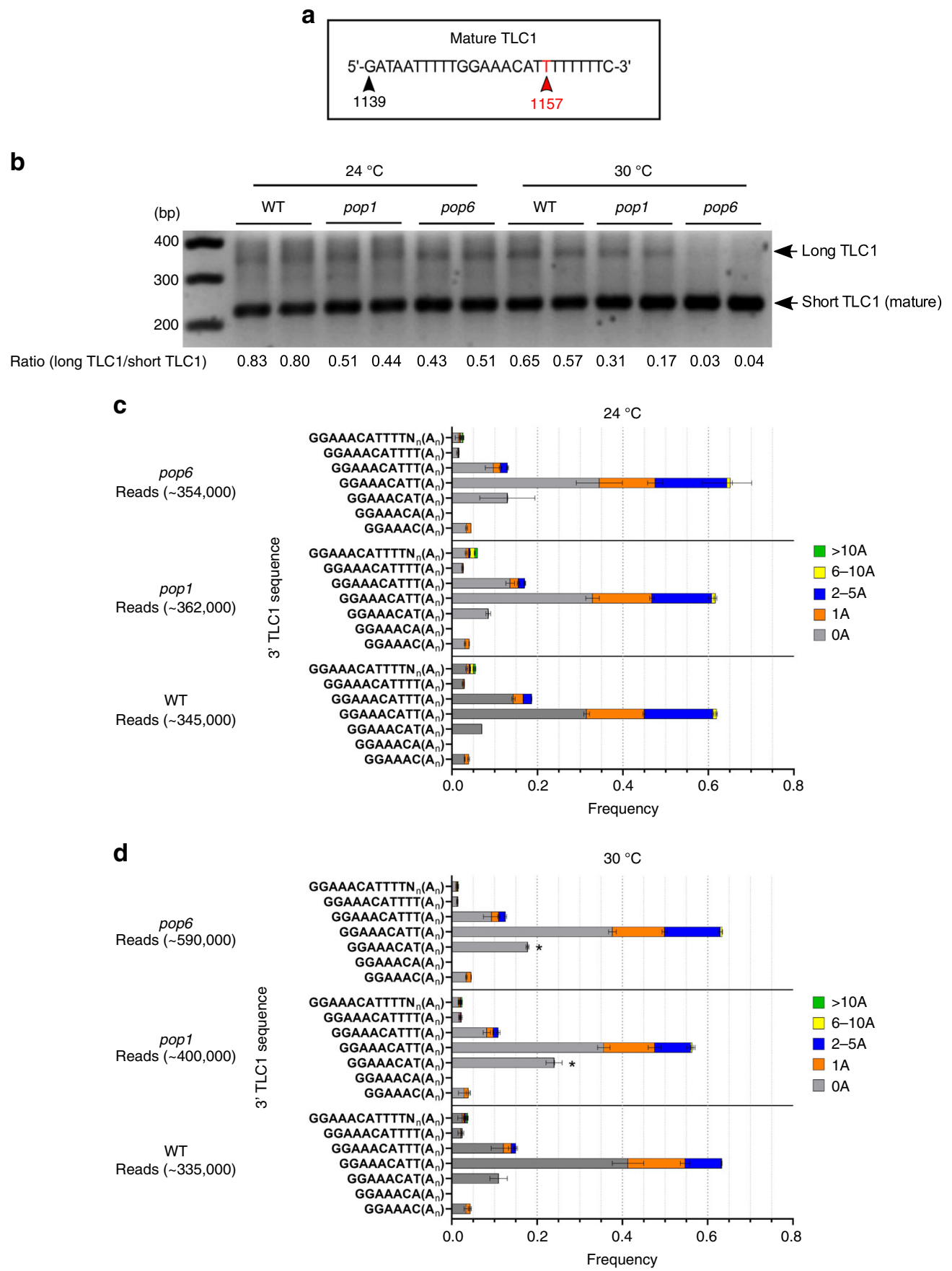

Fig. 6 Processing of TLC1 $3^{\prime}$ ends is not altered in pop cells at $24^{\circ} \mathbf{C}$. The $3^{\prime}$ end sequences of TLC1 extracted from 24 or $30^{\circ} \mathrm{C}$ grown cells were analyzed by 3' RACE. a Diagram of the 3' end of TLC1 from nucleotides 1139 to 1164. The last nucleotide in the 1157 nt mature TLC1 molecule is indicated with a red arrowhead. b PCR products amplified from TLC1 CDNA were analyzed on a 1\% agarose gel. The expected sizes of mature and precursor forms of TLC1, are, respectively, $\sim 220$ and $\sim 350 \mathrm{bp}$. Compared to WT, the relatively abundance of short to long forms were higher in pop1 and pop 6 cells at $24{ }^{\circ} \mathrm{C}$ and, especially, $30^{\circ} \mathrm{C}$. Ratios of long to mature form are shown below lanes. All amplicons $<500$ nts shown in panel B were purified and deep sequenced. The relative abundance of each TLC1 species as determined by sequencing was quantified. Sequences that aligned to the 1154 to $>1159 \mathrm{nt}$ end of TLC1 with or without a poly (A) tail are shown for cells grown at $\mathbf{c} 24^{\circ} \mathrm{C}$ or $\mathbf{d ~} 30^{\circ} \mathrm{C}$. The size of the poly(A) tails are: no adenosine (gray), 1 adenosine (orange), $2-5$ adenosines (dark blue), 6-10 adenosines (yellow) and $>10$ adenosines (green). Total reads are indicated. Each bar shows the average from biological duplicates. At $30^{\circ} \mathrm{C}$, transcripts ending at nt 1156 [no poly(A)] were significantly more abundant by an unpaired two-tailed Student's $t$-test in pop1 and pop6 versus WT (marked with asterisk). Source data are provided as a Source Data file.

As expected, the structure of NME1 was highly Pop sensitive. At $24^{\circ} \mathrm{C}$, there were four regions that had significantly different DMS reactivity in pop versus WT cells (Fig. 8a-c; Supplementary Fig. 4). Region one (nucleotides 37-42) localized to the P3 stem loop where Pop6 and Pop7 bind (Fig. 8a, c; Supplementary Fig. 4). The three other differentially reactive regions were located throughout NME1 (nucleotides 93-121, region two; nucleotides 146-152, region three; nucleotides 247-277, region 4; Fig. 8a, c). Thus, $26 \%$ of the 256 nts analyzed in NME1 met the criteria for differential reactivity in pop versus WT cells. At $30^{\circ} \mathrm{C}$, there were two 
a

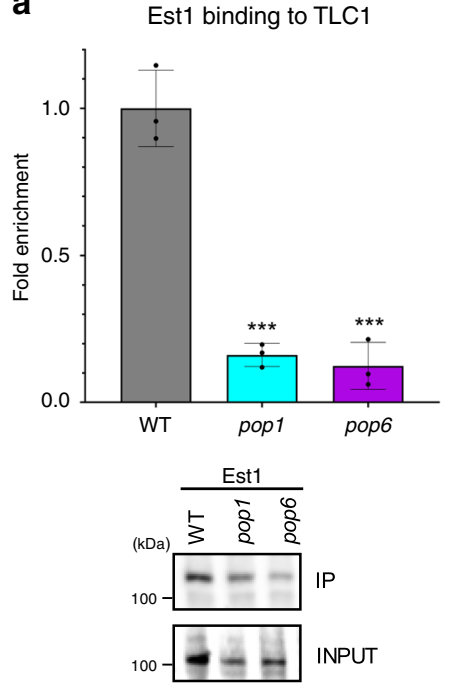

c

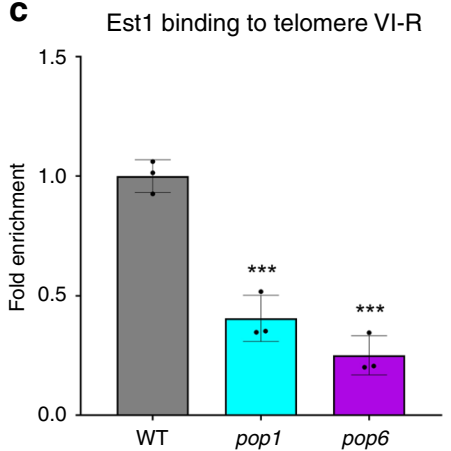

d

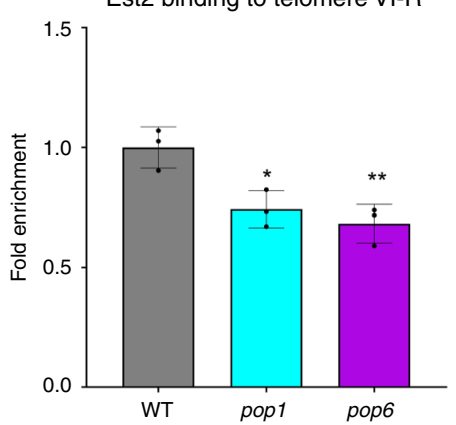

b Est2 binding to TLC1
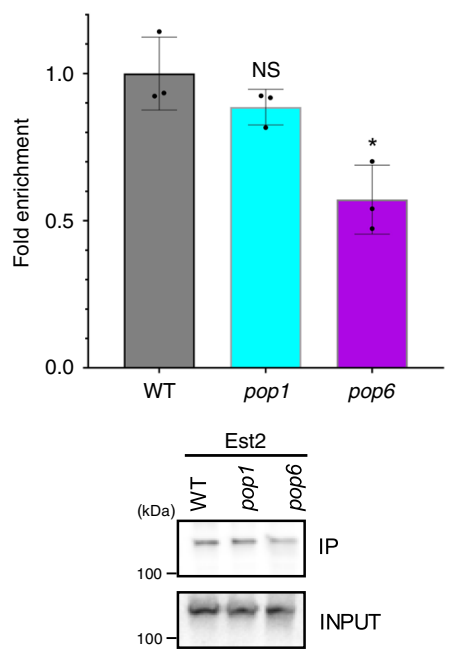
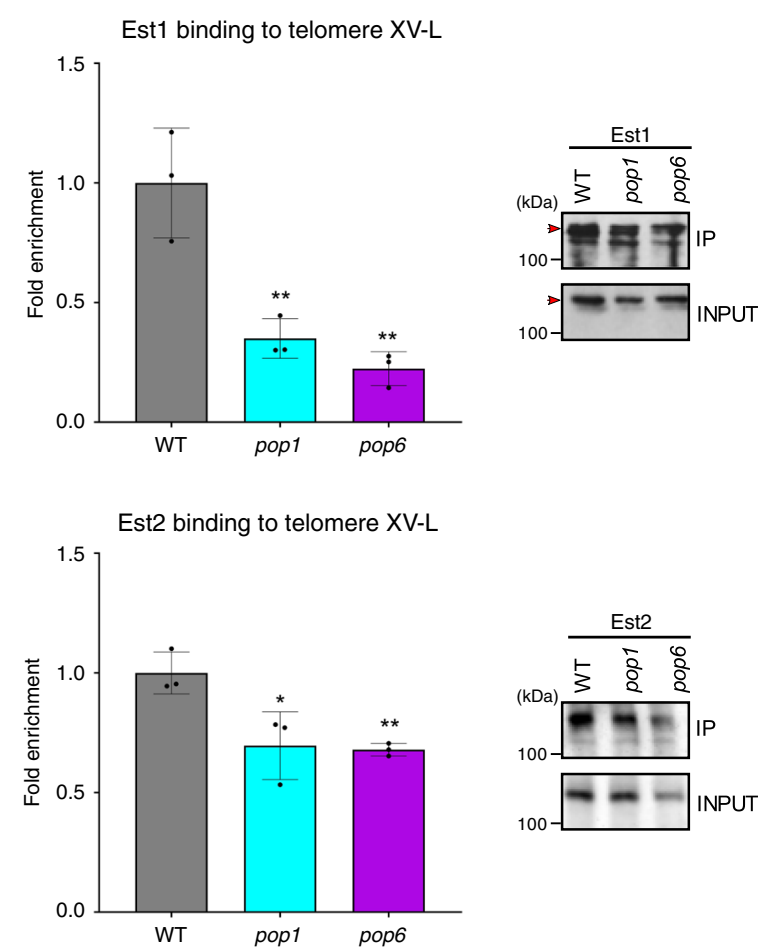

Fig. 7 Telomerase holoenzyme assembly and telomerase binding to telomeres is deficient in pop cells at $24^{\circ} \mathrm{C}$. RNA immunoprecipitations were done in WT (gray bars), pop1 (blue bars) and pop6 (purple bars) cells expressing a Est1-MYC or b Est2-MYC. Extracts prepared from cells grown at $24{ }^{\circ} \mathrm{C}$ for $\sim 50$ generations were immuno-precipitated with anti-MYC antibody, and the amount of TLC1 in each precipitate was determined by RT-qPCR. The IP/INPUT levels of TLC1 were normalized to the IP/INPUT levels of ACT1 mRNA in each sample. The average TLC1/ACT1 ratios in WT cells were defined as one. Fold enrichment and significance in pop cells is relative to WT. Chromatin immunoprecipitation assays in WT, pop 1 and pop 6 cells grown at $24{ }^{\circ} \mathrm{C}$ for $\sim 50$ generations to determine the association of $\mathbf{c}$ Est1-MYC or $\mathbf{d}$ Est2-MYC to telomeres VI-R (left) and XV-L (right). The level of telomeric sequence in the IP/ INPUT was normalized to the amount of ARO1 DNA in the IP/INPUT of the same sample. The average ratio of telomeric DNA to ARO1 in WT cells is defined as one. Fold enrichment and significance in pop1 and pop6 cells is relative to WT. Western blots of Est1-MYC or Est2-MYC in both the input and immuno-precipitates (IP) demonstrate that similar amounts of Est1 and Est2 were immuno-precipitated in WT and pop cells at $24{ }^{\circ} \mathrm{C}$. Red arrowheads in c) indicate the band for Est1-Myc. Biological replicates in a-d are shown as black circles. Error bars are one standard deviation from the average value of three or more independent experiments. $P$-values were calculated using unpaired two-tailed Student's $t$-test; ${ }^{\star} P \leq 0.05,{ }^{\star \star} P \leq 0.01,{ }^{\star \star \star} P \leq 0.001,{ }^{\star \star \star \star} P \leq 0.0001$; NS, not significant, $P>0.05$. Source data are provided as a Source Data file.

additional regions of statistically significant modification in the pop6 strain (Supplementary Figs. 5-7). Thus, the structure of NME1 RNA is globally altered in pop 1 and pop 6 cells even at $24^{\circ} \mathrm{C}$.

Unexpectedly, TLC1 had a single, short region that was differentially DMS reactive in pop versus WT cells at $24^{\circ} \mathrm{C}$ (Fig. 8d; Supplementary Fig. 9). The altered region consisted of only seven nucleotides in the P3-like CS2a domain where Pop6 and Pop7 bind (Fig. 8e). The higher DMS reactivity of these nucleotides can be explained by a reduction in Pop $1 / 6$ binding that normally shields them from DMS modification (Fig. 1a). This lower binding is expected as Pop1 was present at $~ 45 \%$ of WT levels in pop 1 and pop 6 cells at $24^{\circ} \mathrm{C}$ (Fig. 2f, g). There were 
a
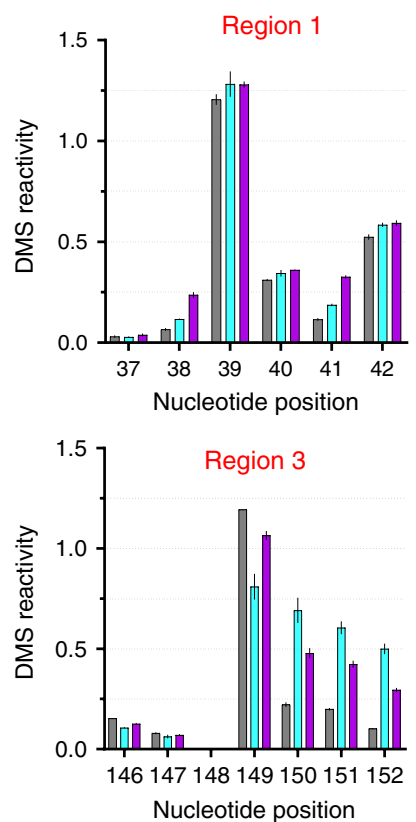

b

\begin{tabular}{|l|l|l|l|}
\hline \multirow{2}{*}{ Calculated $q$ values and $\Delta d$ for regions $1-4$} \\
\hline \multirow{2}{*}{ Region 1 } & & pop1 & pop6 \\
\cline { 2 - 4 } & q value & 0.05 & 0.05 \\
\hline \multirow{2}{*}{ Region 2 } & $q$ value & $2 \times 10^{-4}$ & $2 \times 10^{-4}$ \\
\cline { 2 - 4 } & $\Delta d$ & 0.3 & 0.2 \\
\hline Region 3 & $q$ value & 0.04 & 0.04 \\
\cline { 2 - 4 } & $\Delta d$ & 0.2 & 0.1 \\
\hline \multirow{2}{*}{ Region 4 } & $q$ value & $3 \times 10^{-3}$ & $2 \times 10^{-3}$ \\
\cline { 2 - 4 } & $\Delta d$ & 0.1 & 0.1 \\
\hline
\end{tabular}

d

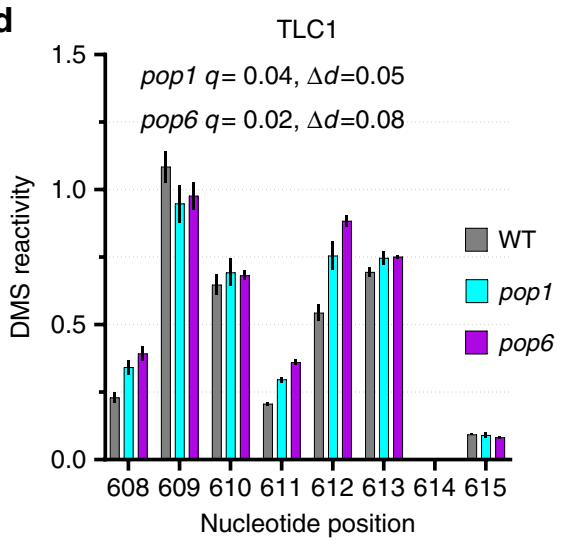

no other significant changes in DMS reactivity in the 710 nucleotides of TLC1 examined, including the binding sites for Est1, Est2, Yku, the $\mathrm{Sm}_{7}$ ring and the template region (Supplementary Figs. 8-10). Thus, fewer than $1 \%$ of the analyzed nucleotides in TLC1 met the criteria for being differentially reactive in pop versus WT cells compared to $26 \%$ in NME1. The WT DMS sensitivity of the Est 1 and Est2 binding sites is consistent with the near WT levels of Est1 and Est2 in pop cells at $24^{\circ} \mathrm{C}$ (Fig. 4a-d).
NME1

Region 2
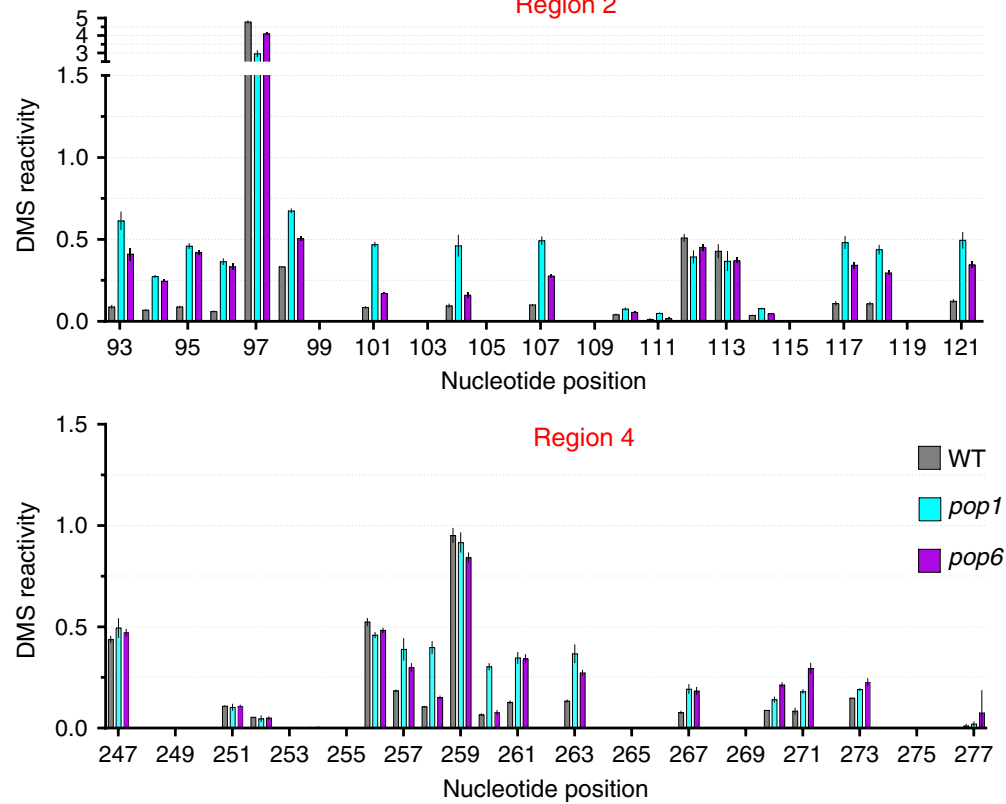

C

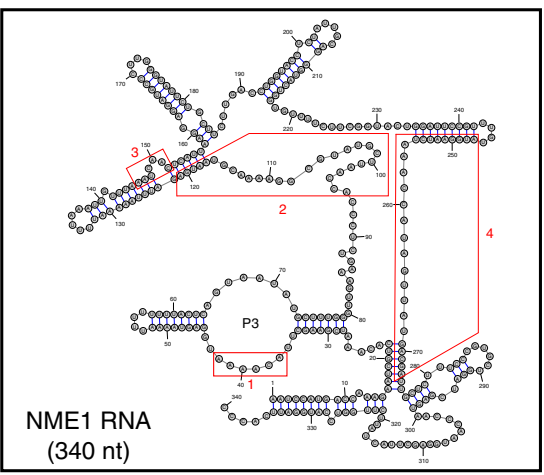

e

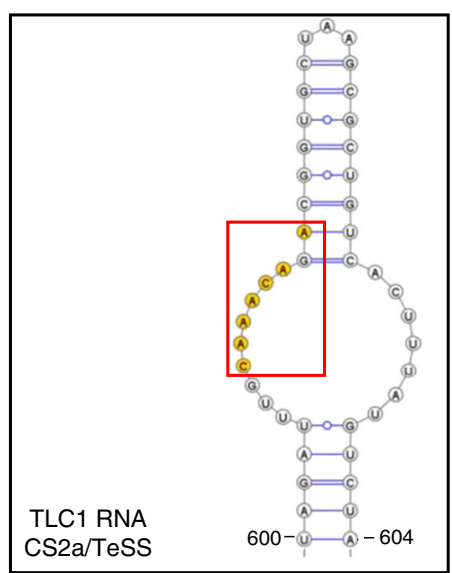

At $30^{\circ} \mathrm{C}$, there were three overlapping regions with differential reactivity in TLC1 in both pop strains, including the binding site for Est1, and two additional regions seen only in pop1 or pop6 cells (Supplementary Figs. 11-14). We conclude that Pop proteins affect the global structure of NME1 but not TLC1 at $24^{\circ} \mathrm{C}$. The similarity in DMS-reactivity of the Est 1 and Est 2 binding sites in pop and WT cells at $24^{\circ} \mathrm{C}$ suggest that Est1 and Est2 are TLC1associated at near WT levels in vivo at this temperature. In contrast, the altered DMS reactivity of the Est1 binding site in pop 
Fig. 8 The global structure of NME1 but not TLC1 is affected in pop cells at $24^{\circ} \mathbf{C}$. DMS-MaPseq analysis from strains grown at $24{ }^{\circ} \mathrm{C}$ for $\sim 50$ generations. a Four regions of NME1 RNA with statistically significant different DMS reactivities in pop1 (blue bars) and pop6 (purple bars) compared to WT (gray bars) cells are shown. DMS reactivities from three independent biological replicates were averaged. $\mathbf{b} q$ Values and $\Delta d$ values of regions 1-4 of NME1 RNA in pop1 and pop6 compared to WT cells. Regions of five nucleotides (or more) that had q-values $<0.1$ and $\Delta d>0.01$ were considered statistically significant. $\mathbf{c}$ The four regions shown in (A) are mapped onto the NME1 RNA structure ${ }^{23}$; region numbers are the same as in $\mathbf{a}$. The significantly altered regions are denoted by red boxes. $\mathbf{d}$ Average normalized DMS reactivity from nucleotides 608-615 in TLC1. These nucleotides are at the site of Pop6/7 binding. Symbols are the same as in panel A. $q$ values and $\Delta d$ values of the indicated region in pop1 and pop6 compared to WT. e Enlarged view of the CS2a/TeSS domain of TLC1 indicated in d. Nucleotides in orange indicate the only nts in TLC1 that met the criteria for being differentially reactive. See supplementary Figs. 4-7 for DMS reactivity in regions where there was no significant difference between pop mutants and WT. Source data are provided as a Source Data file.

cells at $30{ }^{\circ} \mathrm{C}$, suggests that binding of Est1 was reduced at the higher temperature. This conclusion is consistent with the reduced abundance of Est 1 at $30^{\circ} \mathrm{C}$ (Fig. $4 \mathrm{a}, \mathrm{c}$ ).

At first glance, the $24^{\circ} \mathrm{C}$ data from RNA-IP (Fig. 7a,b) and DMS-MaPseq (Fig. 8; Supplementary Figs. 8-10) appear contradictory. By RNA-IP, only $\sim 14 \%$ of TLC1 RNA was Est1 associated. However, by DMS-MaPseq, the Est1 binding site had a WT structure suggesting similar levels of Est1 binding to TLC1 in pop and WT cells at $24^{\circ} \mathrm{C}$. As detailed in the discussion, the two methods monitor different aspects of the Est1-TLC1 association. DMS-MaPseq monitors Est1-TLC1 binding in vivo. RNA-IP detects Est1-TLC1 associations that are sufficiently stable to persist for the time needed to process the cellular lysate.

TLC1 re-localization to the nucleus is impaired in pop cells. Although an unstable holoenzyme that has reduced telomere binding can explain the short telomere phenotype of pop cells, it does not explain the increased abundance of TLC1. High levels of TLC1 are not due to faulty RNA processing (Figs. 5, 6) nor to its global mis-folding (Fig. 8; Supplementary Figs. 8-10). However, if an unstable holoenzyme is less likely to be imported back to the nucleus, TLC1 might accumulate in the cytoplasm where it would not be accessible to the nuclear exonucleases that degrade $i^{42}$. To test this possibility, we used RNA FISH to determine if Pop deficiency altered the sub-cellular distribution of TLC1.

To detect TLC1, we used a Cy3-labeled (green) 52-nts long DNA probe complementary to nts 389 to 414 of TLC1. The probe contains a 26 nts sequence that binds TLC1 including a 10-nts toehold and a 16-nts stem that forms a hairpin-like structure with a 10 -nts loop (Fig. 9a) ${ }^{43}$. When the 10 nts portion binds TLC1, the stem region unzips only for a fully matching RNA molecule allowing stable hybridization (Fig. 9a). A probe containing a hairpin has a higher target specificity than an unmasked probe with the same cognate sequence ${ }^{1,43,44}$ (Supplementary Figs. 15 and 16). The nucleolus was detected with a similarly structured Cy5-labeled (red) FISH probe that targeted the transcribed spacer ITS1 in the $35 \mathrm{~s}$ rRNA precursor RNA ${ }^{45}$. The specificity of the TLC1 probe was demonstrated by its very low signal in $t l c 1 \Delta$ cells (Supplementary Fig. 17). FISH spots arose predominately from single RNA molecules as evident from single-step photobleaching (Supplementary Fig. 18). The nucleus was stained with DAPI, and cell size was determined by DIC microscopy. (See Fig. 9a and Supplementary Fig. 19 for representative images.) TLC1 spots that colocalized with Cy5 and DAPI were categorized as nucleolar and nuclear, respectively. Spots that colocalized with neither but were present within the boundaries of a cell were categorized as cytoplasmic. Our values for TLC1 distribution in nuclear versus cytoplasmic fractions were similar to those reported by others for WT cells when our values for TLC1 in the nucleolar and nucleoplasmic fractions were combined ${ }^{46}$.

The average number of Cy3-labeled FISH spots per cell at $24^{\circ} \mathrm{C}$ was $\sim 9$ (WT), 23 (pop $1 ; 2.7 \times \mathrm{WT}$ ), and 16 (pop6; 1.9× WT) (Fig. 9b, d). For each strain, the number of TLC1 spots was higher at $30^{\circ} \mathrm{C}$ than at $24^{\circ} \mathrm{C}(10.5$, WT; 31 or $3 \times$ WT, pop 1 ; 48 or $4.6 \times$ WT, pop6). The fold increase in TLC1 RNA in $p o p$ compared to WT cells was significant at both temperatures (all $P$-values $<0.005)$ and remarkably consistent with fold increases in TLC1 as determined by RT-qPCR (Fig. 4e). The number of detected TLC1 FISH spots per WT cell $(\sim 11)$ is smaller than the number of TLC1 molecules per cell (29) as determined by a biochemical assay ${ }^{8}$. This lower number agrees with previous studies that also showed substoichiometric detection efficiency with this FISH protocol ${ }^{47}$.

We determined the number of TLC1 molecules in the nucleoplasm, the nucleolus and the cytoplasm in WT and pop cells at $24^{\circ}$ and $30^{\circ} \mathrm{C}$ (Fig. 9c, d). Compared to WT, the fraction of TLC1 molecules in the nucleolus in pop cells at both $24^{\circ} \mathrm{C}$ and $30^{\circ} \mathrm{C}$ was not significantly different from WT (Fig. 9d). However, in both pop strains, there was a significantly larger fraction of TLC1 molecules in the cytoplasm compared to WT cells. This difference was significant at both $24^{\circ} \mathrm{C}$ and $30^{\circ} \mathrm{C}$ but was exacerbated at $30^{\circ} \mathrm{C}$ (fraction of cytoplasmic TLC1: 0.32 , WT vs $\sim 0.40$, pop cells at $24^{\circ} \mathrm{C} ; 0.28$, WT vs $\sim 0.52$, pop cells at $30^{\circ} \mathrm{C}$ ). We conclude that the transit of TLC1 from the cytoplasm back to the nucleus is impaired in pop 1 and pop6 cells.

\section{Discussion}

Pop proteins have been known for decades owing to their essential functions as protein subunits of two RNA-multi protein complexes, RNAse P and MRP. Here, we examine the significance of the unexpected finding that Pop1, Pop6, and Pop7 are telomerase associated ${ }^{5,22}$. RNase $\mathrm{P}$, the better studied of the two complexes, is mostly known for its ubiquitous role in tRNA processing. However, non-tRNA targets have been identified in bacteria, yeast, and humans ${ }^{23}$. For example, RNase $\mathrm{P}$ cleavage generates the mature $3^{\prime}$ end of the human MALAT1 non-coding RNA that is mis-regulated in many cancers ${ }^{48}$. The role of Pop proteins on TLC1 is fundamentally different from the role of RNase P at other atypical substrates, as it involves only three of the nine protein subunits of RNase $\mathrm{P}^{5}$. Moreover, Pop proteins did not affect the processing of TLC1 as formation of the $5^{\prime}$ and $3^{\prime}$ ends of TLC1 were unchanged in pop cells, even at $30^{\circ} \mathrm{C}$ (Figs. 5 and 6). These results raise the possibility that Pop proteins may act non-catalytically on other RNA-protein complexes.

To study how Pop proteins affect TLC1, we reduced the abundance and activity of Pop1 or Pop6 using temperature sensitive alleles (Fig. 2a). At $24^{\circ} \mathrm{C}$, pop 1 and pop6 cells grew about as well as WT (Fig. 2c), and the abundance of many proteins (Fig. 2e), including telomerase subunits Est1 and Est2 (Fig. 4a-e), were similar to WT levels. In contrast, at $24^{\circ} \mathrm{C}$, mutant Pop1 was present at $\sim 45 \%$ of WT levels. Studying pop mutants at permissive temperature almost surely underestimates their impact on telomeres and telomerase. However, this strategy makes it likely that telomerase defects are due to direct effects of altered Pop proteins rather than to a general decline in protein synthesis. 'Even though our approach was conservative, we detected multiple, statistically 


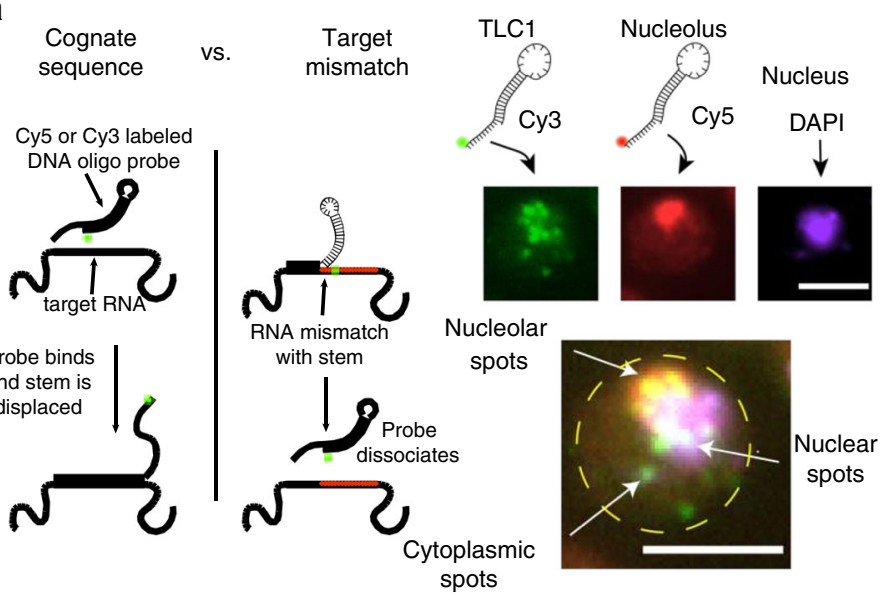

b

C $24^{\circ} \mathrm{C}$
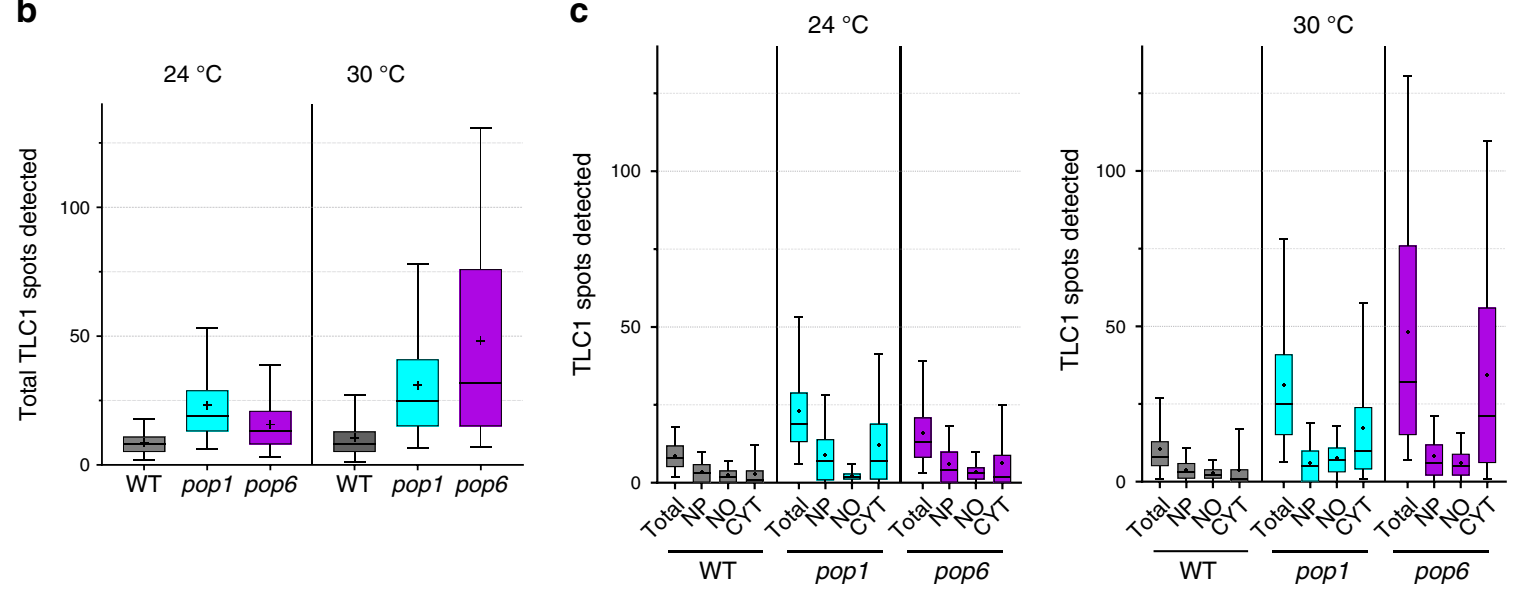

d $24^{\circ} \mathrm{C}$

\begin{tabular}{|c|c|c|c|c|c|}
\hline & & Total & $\mathrm{NP}$ & NO & $\mathrm{CYT}$ \\
\hline \multirow{2}{*}{ WT } & Spotss . & $8.7 \pm 0.3$. & $3.7 \pm 0.2$. & $2.4 \pm 0.1$ & $2.6 \pm 0.2$ \\
\hline & Fraction & 1 & $0.4 \pm 0.01$ & $0.28 \pm 0.01$ & $0.32 \pm 0.01$ \\
\hline \multirow{2}{*}{ pop1 } & . Sppots . & $23.1 \pm 0.7^{\star * *}$ & $9.0 \pm 0.4 * * *$ & . 2:2 $20.1 \mathrm{NS}$ & $\ldots 12 . \pm 0.7^{* * \star *}$ \\
\hline & Fraction & 1 & $0.44 \pm 0.02$ ** & $0.11 \pm 0.01 \mathrm{NS}$ & $0.44 \pm 0.02^{* * \star *}$ \\
\hline \multirow{2}{*}{ pop6 } & Sppots . & $16 \pm 0.6$. & $6.1 \pm 0.3 \mathrm{NS}$ & . . & $\ldots 6.3 \pm 0.5 * \ldots$ \\
\hline & Fraction & 1 & $0.39 \pm 0.01 \mathrm{NS}$ & $0.26 \pm 0.01 \mathrm{NS}$ & $0.35 \pm 0.020^{* *}$ \\
\hline
\end{tabular}

$30{ }^{\circ} \mathrm{C}$

\begin{tabular}{|c|c|c|c|c|c|}
\hline & & Total & NP & NO & CYT \\
\hline \multirow{2}{*}{ WT } & Spots & $10.5 \pm 0.6$ & $3.9 \pm 0.2$ & $2.8 \pm 0.1$ & $3.8 \pm 0.5$ \\
\hline & Fraction & 1 & $0.39 \pm 0.01$ & $0.32 \pm 0.01$ & $0.28 \pm 0.02$ \\
\hline \multirow{2}{*}{ pop1 } & .Spots . . & $31.0 \pm 2.0 * * *$ & $\ldots .1 \pm 0.5{ }^{*} \ldots$ & $7: 7 \pm 0.4 \mathrm{NS}$ & $17.2 \pm 1.7^{* * *}$ \\
\hline & Fraction & 1 & $0.23 \pm 0.01 \mathrm{NS}$ & $0.30 \pm 0.01 \mathrm{NS}$ & $0.46 \pm 0.02$ ** \\
\hline \multirow{2}{*}{ pop6 } & Spots & $48.3 \pm 2.7^{* *}$ & $8.2 \pm 0.5^{*}$ & $6.1 \pm 0.3 \mathrm{NS}$ & $34.4 \pm 2.3^{* * \star *}$ \\
\hline & Fraction & $\begin{array}{c}1 \\
1\end{array}$ & $0.23 \pm 0.02 \mathrm{NS}$ & $0.19 \pm 0.01 \mathrm{NS}$ & $0.58 \pm 0.02$ * \\
\hline
\end{tabular}

Fig. 9 Re-entry of TLC1 RNA into the nucleus is impaired in pop cells. a Schematic of the FISH method. FISH probes have a hairpin structure. Specificity is enhanced by strand displacement of the stem by the cognate RNA, but any mismatch in the target inhibits initial binding or strand displacement. TLC1 (green) is targeted by a short 52-nt DNA Cy3-labeled probe; ITS1 (red), nucleolar RNA, is targeted with a Cy5-labeled 52-nt oligo probe. The nucleus (purple) is visualized with DAPI. A composite image of a pop 6 cell is shown from the overlap of 3 channels. TLC1 spots are assigned a localization based on the overlap with the intensity in the other two channels. Scale bar: $5 \mu \mathrm{m}$. $\mathbf{b}$ Total number of FISH spots per cell in cells grown at $24{ }^{\circ} \mathrm{C}$ and $30^{\circ} \mathrm{C}$. The number of cells analyzed per strain ranged from 328 to 538. c Spot distributions for subcellular compartments. Nucleoplasm (NP), Nucleolus (NO), Cytoplasm (CYT). Whiskers on distributions represent the 5 and $95 \%$ percentiles, the box extends from 25 to $75 \%$, the middle of the box represents the median and the + sign represents the mean. $\mathbf{d}$ Spots and fractions indicate the mean and standard error of FISH TLC1 spots per cell. Fractions were calculated by normalizing the TLC1 spots in each subcellular compartment by the total number of TLC1 spots per cell. P values were calculated using the Kolmogorov-Smirnoff two sample test. Black asterisks indicate significance of difference in spot numbers in pop1 or 6 versus WT cells; red asterisks indicate significance of difference in fraction of spots in pop1 or 6 versus WT cells. Because the fraction of TLC1 in the NO was low, a two-fold fractional change in nucleolar TLC1 in pop1 versus WT at $24^{\circ} \mathrm{C}$ was not significant. Source data are provided as a Source Data file. 
significant effects on the abundance and structure of TLC1 and NME1.

Mutation of either Pop1 or Pop6 led to dramatic effects on telomeres and telomerase at $24^{\circ} \mathrm{C}$. These effects were exacerbated at $30^{\circ} \mathrm{C}$. Compared to WT, telomere lengths at $24^{\circ} \mathrm{C}$ were reduced by $\sim 27-40 \%\left(30-50 \%\right.$ reduction at $30^{\circ} \mathrm{C}$ ) (Fig. 3 ). Short telomeres were not due to reduced levels of three key telomerase subunits. At $24^{\circ} \mathrm{C}$, Est 1 and Est 2 were present at close to WT levels, while levels of TLC1 were twice as high in pop compared to WT cells $\left(4-6 \times \mathrm{WT}\right.$ at $30^{\circ} \mathrm{C}$; Fig. 4e). However, like tubulin and Pgk1 (Fig. 2e, f), Est1/2 levels were reduced at $30^{\circ} \mathrm{C}(0.4 \times \mathrm{WT})$ (Fig. 4a, c).

Reduced Pop proteins had very different effects on TLC1 versus NME1 RNA. While levels of TLC1 were elevated, NME1 was reduced to $\sim 50 \%$ of its WT levels in pop cells at $24^{\circ} \mathrm{C}(25 \%$ of WT at $30^{\circ} \mathrm{C}$; Fig. $\left.4 \mathrm{f}\right)$. The reduction in NME1 is likely due to the global disruption of its structure, as by DMS-MaPseq analysis, $26 \%$ of the examined $\mathrm{C}$ and A's in NME1 were differentially DMS-sensitive at $24^{\circ} \mathrm{C}$ (Fig. 8). These structural changes probably target NME1 for degradation. In contrast, only seven nts in TLC1, fewer than $1 \%$ of those examined, were differentially reactive to DMS at $24^{\circ} \mathrm{C}$ in pop cells (Fig. 8d; Supplementary Figs. 8-10). These seven nucleotides are the site of Pop binding ${ }^{22}$. Their higher reactivity is easily explained by their being less protected from DMS in pop cells owing to the reduction and/or altered activity of Pop proteins (Fig. 2f, g). In contrast, the Est1 binding site, which is very close to the Pop binding site, was not altered by Pop deficiency at $24^{\circ} \mathrm{C}$ (Supplementary Fig. 9). Likewise, the Est2, Yku, and $\mathrm{Sm}_{7}$ binding sites had WT DMS sensitivity (Supplementary Figs. 8-10). Although it is possible that some changes in DMS accessibility were below detection, the large number of reads, reproducibility between replicates and statistical methods allow detection of differences that occur in only a subset of molecules ${ }^{39-41}$. Moreover, using the same DMSMaPseq method, the Est1 binding site in TLC1 was differentially DMS-sensitive at $30^{\circ} \mathrm{C}$ (Supplementary Figs. 11-14). At this temperature, Est 1 levels were reduced $(0.4 \times$ WT, Fig. $4 \mathrm{~b}, \mathrm{~d})$. The altered DMS reactivity of the Est1 binding site at $30^{\circ} \mathrm{C}$ is probably explained by this site being less protected from DMS owing to lower binding by Est1 (Supplementary Figs. 12 and 14). Taken together, the DMS-MaPseq data indicate that Est1 and Est 2 are TLC1-associated to similar extents in WT and pop cells at $24^{\circ} \mathrm{C}$.

We also studied Est1 and Est 2 binding to TLC1 using RNA-IP (Fig. 7a, b). By this assay, the fraction of TLC1 molecules that were Est1 associated in pop cells at $24^{\circ} \mathrm{C}$ was only $\sim 14 \%$ of WT (Fig. 7a). By the RNA-IP assay, Est2-TLC1 binding was also reduced, but the reduction was significant only in pop6 cells ( $\sim 60 \%$ of WT; Fig. $7 \mathrm{~b}$ ). Telomerase binding to telomeres was also significantly impaired $\left(\sim 70 \%\right.$ of WT at $24^{\circ} \mathrm{C}$; Fig. $\left.7 \mathrm{c}, \mathrm{d}\right)$. The more dramatic effects of Pop proteins on Est1 (compared to Est2) could be related to its cell cycle regulated abundance and telomere binding ${ }^{2,3}$. In contrast, Est2 levels are fairly constant, and its association with TLC1 and telomeres occurs throughout much of the cell cycle. In addition, in the two-dimensional TLC1 structure (Fig. 1a), the Pop binding site is much closer to the Est1 than to the Est2 binding site. This greater proximity probably also contributes to the greater Pop-sensitivity of Est1.

The results from DMS-MaPseq (Fig. 8, Supplementary Figs. 8-10), which suggest WT levels of Est1 and Est2 binding to TLC1 in pop cells at $24{ }^{\circ} \mathrm{C}$ seem at odds with the results from RNA-IP (Fig. 7a, b). However, the two assays are very different. DMS modifies RNAs in living cells, whereas, the antibody in RNA-IP is added to a lysate. There is no cross-linking in RNAIP to preserve protein-RNA interactions. If a protein dissociates from TLC1 during isolation, it is unlikely to rebind TLC1 in the lysate. Therefore, DMS accessibility reveals Est1 (and Est2) occupancy on TLC1 at the time the DMS is added, while RNAIP detects only stable Est1/2-TLC1 interactions. The differences in the data in the two experiments are best explained by a model in which Pop proteins stabilize the Est1-TLC1 (and to a lesser extent, the Est2-TLC1) interaction, rather than being required for Est1/2-TLC1 binding. A previous study also used RNA-IP to investigate the association of Est1 and Est 2 to a deletion derivative of $\mathrm{TLC}^{22}$. However, this work did not distinguish a role for Pop proteins in Est1/2-TLC1 binding from a role in stabilization of Est1/2-TLC1 interactions. We conclude that Pop deficiency results in reduced stability of the holoenzyme due to unstable association of Est1 (and hence Est3 and to a much lesser extent Est2) with TLC1. As a result, the holoenzyme is less likely to be telomere-associated and telomeres are short. This interpretation also provides a plausible explanation for the stimulating effects of Pop1 on in vitro telomerase assays ${ }^{22}$. Telomerase activity is similar in extracts from $\mathrm{WT}$, est $1 \Delta$ and est $3 \Delta$ cells $^{49}$. This result is hard to understand given that Est1 is essential to activate telomerase in vivo ${ }^{18}$. The stimulating effects of Pop1 on an in vitro telomerase assay can be explained by its stabilizing the association of Est 1 and hence Est3 (and to a lesser extent Est2) with telomerase. This stimulation should render the normally Est1-independent in vitro reaction Est1-sensitive. This hypothesis could be tested by adding Pop1 to a telomerase extract prepared from est $1 \Delta$ cells.

Although a role for Pop proteins in stabilizing Est1-TLC1 interactions can explain the short telomere phenotype of $p o p$ cells, the increase in TLC1 is hard to understand with this model. Because mature TLC1 associates with Est proteins in the cytoplasm $^{13,15}$, we considered that transit of TLC1 back to the nucleus might be impaired in pop cells. We used RNA FISH to monitor TLC1 localization using atypically structured probes that increase the specificity of the FISH signal ${ }^{47}$ (Fig. 9). The fraction of TLC1 in the nucleolus was similar in pop versus WT cells at $24^{\circ}$ and $30^{\circ} \mathrm{C}$. Thus, consistent with no change in TMG capping (Fig. 5), movement in and out of the nucleolus, did not appear to be affected by Pop deficiency. Although at $24^{\circ} \mathrm{C}$, TLC1 was present in the nucleoplasm in both pop strains, it was significantly over-represented in the cytoplasm in pop1 and pop6 versus WT cells (Fig. 9). This high cytoplasmic localization was exacerbated at $30^{\circ} \mathrm{C}$. Elevated levels of mature TLC1 in pop cells (Fig. 6) support the conclusion from RNA FISH that it accumulates in the cytoplasm, as longer residence in the cytoplasm would protect it from nucleases allowing its copy number to increase. Thus, this work identifies an additional requirement for efficient TLC1 re-entry into the nucleus. That is, when Pop proteins are limiting, TLC1 accumulates in the cytoplasm despite the presence of WT levels of Est proteins and nuclear export factors.

We propose the following model (Fig. 10). Most steps in TLC1 biogenesis, such as RNA processing, occur normally in Pop-deficient cells. However, Pop proteins are required to stabilize the association of Est1 (and hence) Est3 with TLC1. The stable Est2-TLC1 association is also promoted by Pop proteins but to a lesser extent. We propose that the import factors that escort telomerase back to the nucleus in late S/G2 phase recognize some aspect(s) of the holoenzyme. In contrast, the Yku-mediated G1 phase import pathway allows nuclear import of Est2-TLC1-Yku because this pathway does not depend on formation of a stable holoenzyme. By this model, the increase in TLC1 abundance is a secondary consequence of TLC1 mis-localization as the RNase activities that are thought to degrade TLC1 are nuclear-localized (Trf4, a component of TRAMP, and Rrp6, a component of the exosome) ${ }^{42}$. Thus, sequestering TLC1 in the cytoplasm protects it from degradation, resulting in increased copy number. 
a

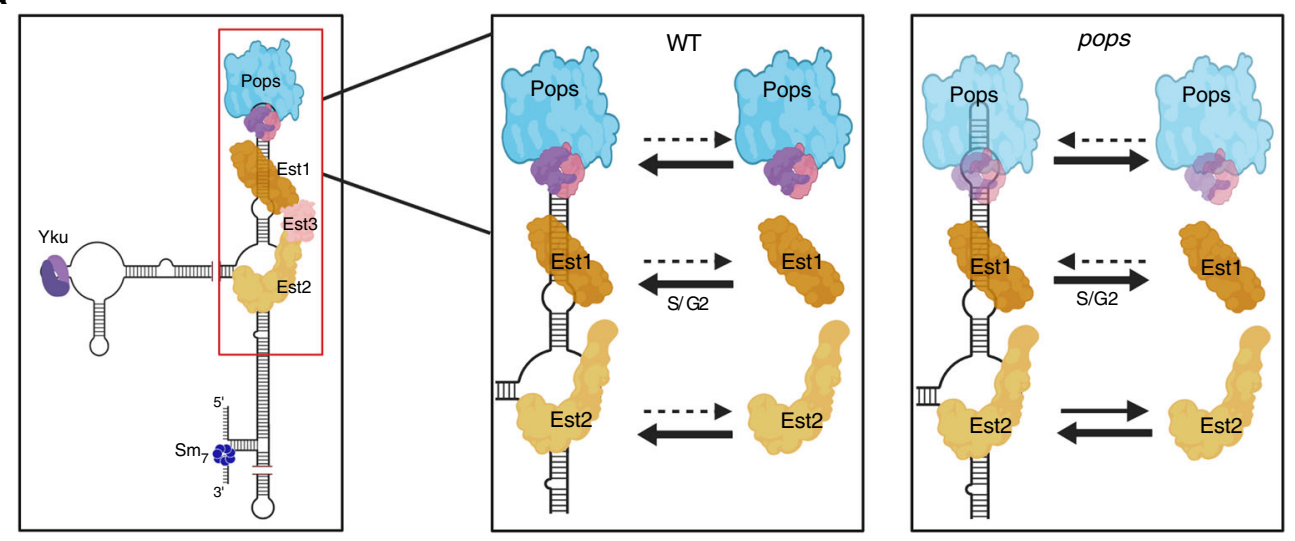

b

G1
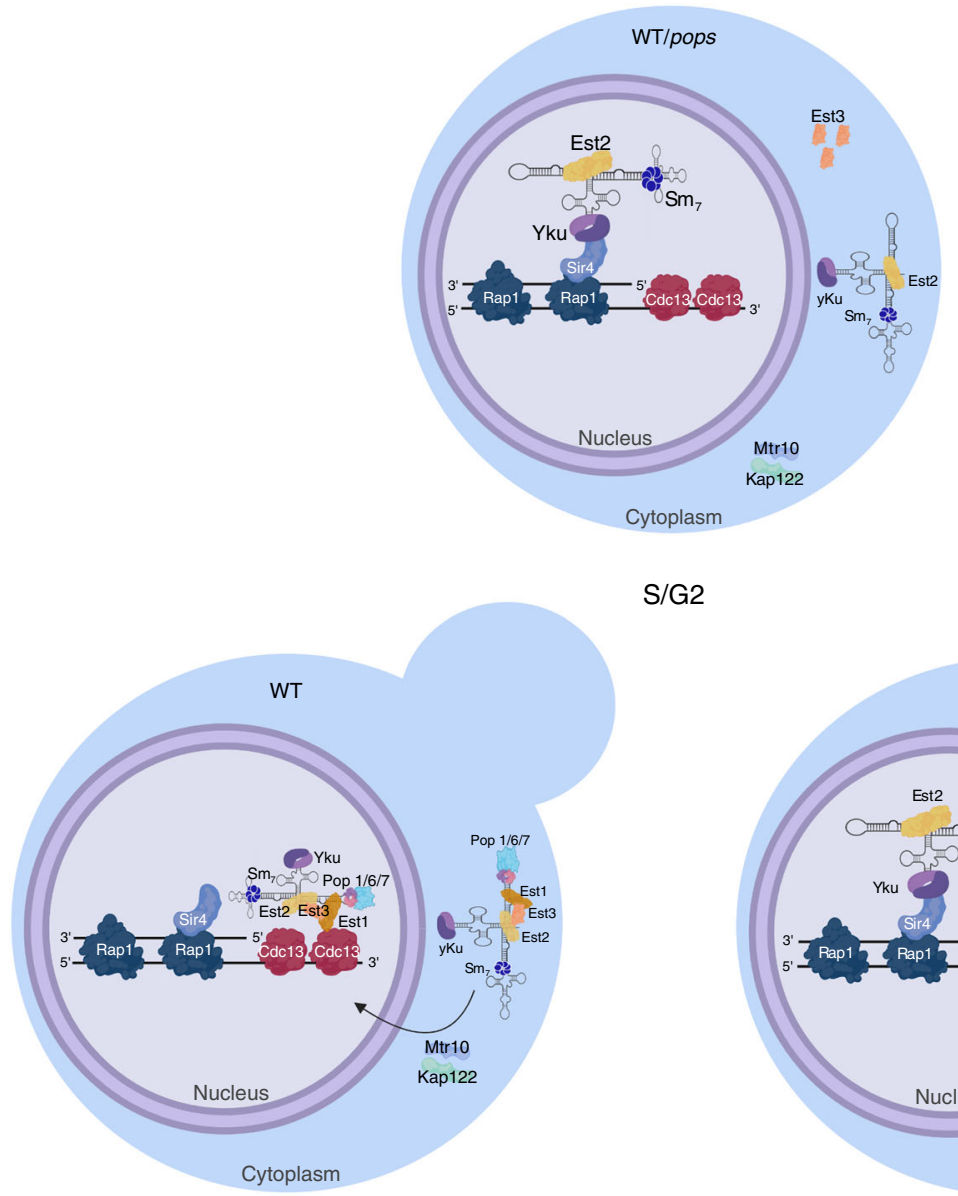

S/G2

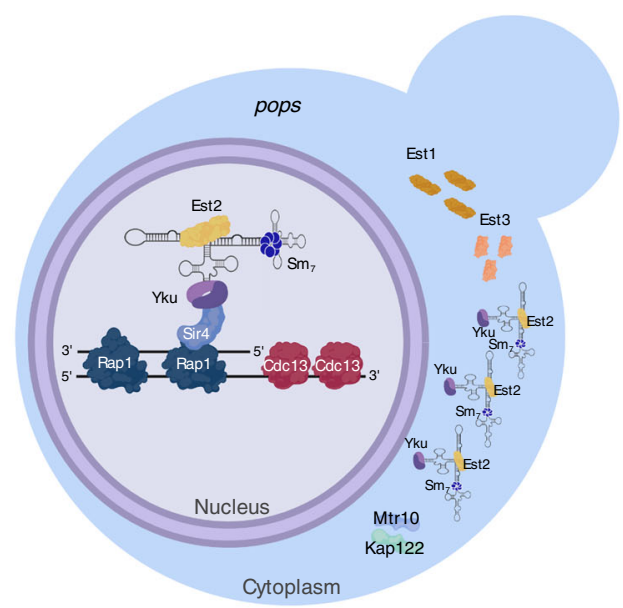

Fig. 10 Working model for how Pop proteins affect the maturation and localization of telomerase. a Our data indicate that the Pop proteins are important to stabilize the binding of Est1 (and hence Est3) (and to a lesser extent Est2) to TLC1 RNA. As the cell progresses into late S phase, reduced levels of Pop1 or Pop6 result in lower amounts of stable holoenzyme. We propose that the import factors that promote the re-entry of TLC1 and its associated proteins to the nucleus recognize only the holoenzyme. As a result, TLC1 accumulates in the cytoplasm in pop cells. b In WT cells, during G1 phase, TLC1 RNA binds to telomeric chromatin via a TLC1-Yku/Sir4/Rap1 interaction ${ }^{3,18}$. The G1 phase binding of telomerase to telomeres is less stable than its association in late $\mathrm{S} / \mathrm{G} 2$ phase ${ }^{20}$. Chromatin bound $\mathrm{G} 1$ telomerase is unable to lengthen telomeres as it lacks two essential subunits, Est1 and Est $3^{2,4}$, and is not engaged at the chromosome end ${ }^{19}$. The abundance of core telomerase subunits is fairly constant throughout the cell cycle except for Est1, whose abundance is low in G1 and peaks in late S/G2 phase $\mathrm{e}^{2,4,6}$ owing to ubiquitin mediated proteolysis ${ }^{5,6}$. Est1 is required to recruit Est3 and form the telomerase holoenzyme 4,6 . Therefore, the telomerase holoenzyme, which assembles in the cytoplasm, is present only in late $S / G 2$ phase. The holoenzyme is transported to the nucleus with the help of import factors such as Mtr10 and Kap12213,14. In late $\mathrm{S} / \mathrm{G} 2$ phase, telomerase engages the singlestrand G-tails via a Cdc13-Est1 interaction. Either the G1 or the late S/G2 recruitment pathway is sufficient to maintain telomeric DNA, but the Cdc13/Est1 interaction is essential for telomerase activation ${ }^{18}$. In both WT and pop cells, the TLC1-Ku/Sir4/Rap1 interactions brings Est2 to telomeres during G1 phase. In late S/G2 phase, reduced levels and/or activity of Pop proteins, lead to instability of the telomerase holoenzyme. The unstable holoenzyme is less likely to be bound by import factors which results in its cytoplasmic accumulation. Images were made in ( $)$ BioRender (biorender.com). 
Although the RNase P/MRP components and their roles in RNA processing have been studied for decades, they have only recently been linked to telomerase ${ }^{5,22}$. As shown here, Pop proteins affect NME1 and TLC1 by very different mechanisms despite the functional interchangeability of the regions to which they bind in the two RNAs ${ }^{22}$. Previous roles for Pop proteins, even on non-canonical substrates, involve RNA processing, yet Pop proteins affect yeast telomerase by a non-catalytic mechanism. The same MS approach that discovered the telomerase association of S. cerevisiae Pop1, 6 and $7^{5}$ found that Schizosaccharomyces pombe Pop1 also co-purifies with epitope-tagged telomerase ${ }^{50}$. Thus, Pop proteins may have conserved functions in telomerase regulation.

\section{Methods}

Yeast strains and methods. S. cerevisiae strains, DNA primers for PCR, and bacterial plasmids are listed in, respectively, Supplementary table 1 (yeast), 2 (plasmids), and 3 (primers). All yeast strains were made in the S288C background. Cells were grown in defined complete (YC) media or in YC minus uracil at $24^{\circ} \mathrm{C}$, $30^{\circ} \mathrm{C}$, or $37^{\circ} \mathrm{C}$. Complementation experiments were done using the URA 3 centromere plasmid pRS416 into which was inserted the entire POP1 or POP6 gene. For this cloning, genes were amplified from yDG199 genomic DNA using primers DG192 and DG193 for POP1 and DG194 and DG195 for POP6. Restriction sites for XhoI and HindIII were designed at the $5^{\prime}$ ends of these primers. PCR amplification was performed with iProof High-Fidelity Polymerase (BIO-RAD) according to the manufacturer's directions. The sequence of the genes was confirmed by sequencing. Transformations were done using the lithium acetate/PEG method ${ }^{51}$. Transformants were selected on YC minus uracil media and grown for $\sim 100$ generations at $24^{\circ} \mathrm{C}$ or $30^{\circ} \mathrm{C}$ before testing phenotypes. Thirteen MYC epitopes were introduced at the carboxyl termini of Est1 and Est2 proteins using plasmid pFA6a-13MYC-HIS3MX6 ${ }^{52}$. To improve the stability of the tagged proteins, a GLY 8 linker was introduced at the $5^{\prime}$ end of MYC-HIS3MX6 ${ }^{53}$. The following primers were used for tagging: DG298 and DG299 for Est1 and DG300 and DG301 for Est2. Wild-type Pop1 and the mutant form of Pop1 were epitope tagged by adding $3 \mathrm{HA}$ at the $\mathrm{N}$-terminus of each protein. WT, pop1 and pop6 strains were transformed with $1 \mu \mathrm{g}$ of a gene block (IDT DNA) that contained homology to the upstream region of $P O P 1$, the HIS3MX6 gene, $300 \mathrm{bp}$ sequence upstream of the POP1 start codon, the $3 \mathrm{HA}$ tag and $\sim 400$ bp downstream of the POP1 start codon Primers used to integrate the 13MYC tag are listed in Supplementary Table 3. To measure growth rates, WT (yDG199), pop1 (yDG190) or pop6 (yDG187) cells were grown at the desired temperatures in $\mathrm{YC}$ media to an $\mathrm{OD}_{600 \mathrm{~nm}}=0.5$, then diluted back to $\mathrm{OD}_{600 \mathrm{~nm}}=0.01$ in prewarmed YC media. The $\mathrm{OD}_{600 \mathrm{~nm}}$ was measured every $2 \mathrm{~h}$ for $24 \mathrm{~h}$.

Southern blots. For telomere length analysis, WT, pop and $k u 70 \Delta$ strains were grown on YC or YC minus uracil plates at $24^{\circ} \mathrm{C}$ or $30^{\circ} \mathrm{C}$ for 100 generations. Three colonies were chosen from each strain and grown in liquid media at $24^{\circ} \mathrm{C}$ or $30^{\circ} \mathrm{C}$. Genomic DNA was extracted from $1.5 \mathrm{mls}$ of saturated cultures $\mathrm{OD}_{600 \mathrm{~nm}}=$ 2.5 using the MasterPure DNA purification Kit (Lucigen MPY80200) as directed by the manufacturer. Southern blots of telomeric DNA were done by extracting $12.5 \mu \mathrm{ls}$ of genomic DNA followed by overnight digestion with XhoI (New England laboratories). XhoI digested DNA and $5 \mathrm{ng}$ of $1 \mathrm{~kb}$ Plus DNA ladder (Invitrogen 10787-018) were run on a $1 \%$ agarose gel in TBE buffer $(45 \mathrm{mM}$ Tris-borate/ $1 \mathrm{mM}$ EDTA), transferred to an Amersham hybond XL membrane (GE Healthcare 106 00003), UV crosslinked and hybridized to a telomeric probe isolated from EcoRI digested pCT300 plasmid ${ }^{54}$. The probe was radiolabeled using the Amersham Rediprime Labelling system (GE Healthcare RPN1633). Blots were visualized using a Typhoon FLA 9500 (GE Healthcare).

Western blots. Protein extraction was done using the whole cell extract method ${ }^{55}$ with some modifications. Briefly, proteins were extracted from $10 \mathrm{mls}$ of culture grown to $\mathrm{OD}_{600 \mathrm{~nm}}=0.5$ at $24^{\circ} \mathrm{C}$ or $30^{\circ} \mathrm{C}$ for $\sim 35$ generations and cells were washed in CE lysis buffer (50 mM HEPES pH 7.5, $140 \mathrm{mM} \mathrm{NaCl}, 1 \mathrm{mM}$ EDTA pH 8.0, 10\% Glycerol, $1 \mathrm{mM}$ DTT and complete, Mini, EDTA-free Protease Inhibitor Cocktail (Roche) and resuspended in $200 \mu \mathrm{ls}$ of CE lysis buffer. Yeast cells were disrupted with glass beads and extracts were resuspended in $50 \mu \mathrm{ls}$ of $2 \mathrm{x}$ SDSPAGE sample buffer (4\% SDS, $20 \%$ glycerol, $120 \mathrm{mM}$ Tris- $\mathrm{HCl} \mathrm{pH}$ 6.8, $0.02 \%$ bromophenol blue and 5\% 2-mercaptoethanol). The samples were then boiled at $95{ }^{\circ} \mathrm{C}$ for $5 \mathrm{~min}$, pelleted, and $10 \mu \mathrm{ls}$ of the supernatant were loaded onto an $8 \%$ acrylamide SDS-PAGE gel. The proteins were transferred to a nitrocellulose membrane (GE Healthcare 106-00063). MYC tagged proteins were detected with a monoclonal c-MYC antibody (1:400 dilution; Takara 631206) and HA tagged proteins were detected with a monoclonal HA antibody (1:1000 dilution; Santa cruz sc-7392). The controls were detected using a monoclonal anti- $\alpha$-tubulin antibody (1:1000 dilution, Sigma T6074) and anti-Pgk1 (1:1000 dilution; Abcam ab113687). Protein detection was done using ECL Prime detection reagents (GE healthcare) according to the manufacturer's directions. The signal was visualized using a FluorChem HD2 Alpha EaseFc system and protein quantification was done using Image J. Western blots of all replicates are shown in the source data file.

RNA extraction and reverse-transcriptase $\mathbf{q P C R}$. Total RNA was extracted from $5 \mathrm{mls}$ of cells grown at $\mathrm{OD}_{600 \mathrm{~nm}}=0.5-0.7$ using $400 \mu \mathrm{ls}$ of TES buffer $(10 \mathrm{mM}$ Tris, $10 \mathrm{mM}$ EDTA, $0.5 \%$ SDS), hot acidic phenol (pH 4.3) saturated with $0.1 \mathrm{M}$ citrate buffer (Sigma-Aldrich P4682), ethanol precipitated and eluted in RNase free water. Five $\mu \mathrm{g}$ of RNA was subsequently DNase treated with Turbo DNA-free (Invitrogen AM107) according to the manufacturer's instructions and eluted with $50 \mu \mathrm{l}$ of elution buffer. cDNA was synthesized from $100 \mathrm{ng}$ of DNase treated RNA using the iTaq Universal SYBR green one-step kit (BIO-RAD 172-5151) and analyzed using a BIO-RAD CFX96 real-time system. The primers used to measure TLC1 (DG293 and DG294), ACT1 (DG52 and DG53) and NME1 (DG330 and DG331) RNAs are listed in Supplementary Table 3. Changes in RNA expression were analyzed from biological triplicates using the $2^{-\Delta \Delta C T}$ method ${ }^{56}$.

RNA immunoprecipitation. Previously described methods with some modifications $^{3}$ were used to measure the binding of Pop1, Est1 and Est2 to TLC1. Briefly, cells expressing HA-Pop1, Est1-MYC or Est2-MYC were collected from $250 \mathrm{mls}$ of culture grown to $\mathrm{OD}_{600 \mathrm{~nm}}=0.5$ at $24^{\circ} \mathrm{C}$. Cell lysis was accomplished with glassbeads in TMG100 buffer (10 mM Tris-Cl pH8, $1 \mathrm{mM} \mathrm{MgCl} 2,10 \%$ glycerol, $100 \mathrm{mM} \mathrm{NaCl}, 0.1 \mathrm{mM}$ EDTA, $0.1 \mathrm{mM}$ DTT). A complete mini EDTA-free protease inhibitor tablet, $20 \mu \mathrm{ls}$ of RNasin Plus RNase Inhibitor (Promega N2618), and $20 \mu \mathrm{ls}$ of SUPERase In RNase Inhibitor (Invitrogen AM2696) were added to $10 \mathrm{mls}$ of TMG100 buffer. For immunoprecipitations, $500 \mu \mathrm{ls}$ of TMG100 plus inhibitors, $0.5 \%$ Tween 20 and $10 \mu \mathrm{ls}$ of monoclonal c-MYC antibody (Takara 631206) or anti-HA (Santa Cruz sc-7392) were added to $1 \mathrm{mg}$ of total protein and incubated overnight at $4{ }^{\circ} \mathrm{C}$. Dynabeads protein $\mathrm{G}$ (Invitrogen) were equilibrated with TMG100 and $0.5 \%$ Tween-20, added to the samples and incubated for $4 \mathrm{~h}$ at $4{ }^{\circ} \mathrm{C}$. After three washes with TMG100 and 0.5\% Tween-20 and one wash with TMG100, the beads were resuspended in TMG100. The IP and INPUT samples were treated with proteinase K (Thermo Fisher 2546), and RNA was extracted with hot acidic phenol method and ethanol precipitated as described above. RNA samples were DNased with Turbo DNA-free (Invitrogen AM107) and eluted with $50 \mu \mathrm{ls}$ of TE buffer.

Chromatin immunoprecipitation. Chromatin immunoprecipitation (ChIP) was performed as previously described with some modification $\mathrm{s}^{57}$. Biological triplicates for each strain were grown in $\mathrm{YC}$ media at $24^{\circ} \mathrm{C}$, and $50 \mathrm{mls}$ of culture $\left(\mathrm{OD}_{600 \mathrm{~mm}}\right.$ $=0.5$ ) were crosslinked with $37 \%$ formaldehyde for $5 \mathrm{~min}$ followed by quenching with $2.5 \mathrm{M}$ glycine for $5 \mathrm{~min}$. Crosslinked samples were lysed with glass-beads using a Fast-prep system (Millipore). Crosslinked DNA was sheared with a Branson 450 sonicator $2 \times 9$ pulses and $50 \%$ output. The sheared samples were then incubated with $10 \mu \mathrm{ls}$ of monoclonal c-MYC antibody (Takara 631206) for one hour at $4{ }^{\circ} \mathrm{C}$. Immunoprecipitation was done using $80 \mu \mathrm{ls}$ of Dynabeads protein $\mathrm{G}$ (Invitrogen) and incubated for $2 \mathrm{~h}$ at $4{ }^{\circ} \mathrm{C}$. After the washes, the samples were reversed-crosslinked overnight in $1 \times \mathrm{TE}$ and $1 \% \mathrm{SDS}$ at $65^{\circ} \mathrm{C}$. The input and immunoprecipitated (IP) DNA were analyzed by quantitative PCR using iQ SYBR Green Supermix (BIO-RAD) with primer pairs DG358 and DG359 for telomere XV-L and primer pairs DG360 and DG361 for telomere VI-R (Supplementary table 3). The following PCR amplification conditions were used: an initial denaturation of $95^{\circ} \mathrm{C}$ for $3 \mathrm{~min}$, and 40 cycles at $95^{\circ} \mathrm{C}$ for $10 \mathrm{~s}$, annealing temperature of $46-55^{\circ} \mathrm{C}$ for $30 \mathrm{~s}$, and extension at $72^{\circ} \mathrm{C}$ for $15 \mathrm{~s}$.

The IP/Input data was normalized to an internal control ARO1 using primers DG362 and DG363. The protein levels of IP and Input samples were analyzed by Western blotting using monoclonal c-MYC antibodies as described above.

Targeted DMS-MaPseq and library preparation. To analyze the structures of TLC1, NME1, and ASH1 RNAs in WT and pop cells, log phase cultures of WT and pop mutants were treated with dimethyl sulfate (DMS; D186309-5ML, Sigma Aldrich), and the RNA was analyzed by targeted RNA sequencing as previously described ${ }^{36}$ with some modifications. Briefly, biological triplicates of the WT, pop1 and pop6 cells were grown in $\mathrm{YC}$ media at $24^{\circ} \mathrm{C}$ or $30^{\circ} \mathrm{C}$ to $\mathrm{OD}_{600}=0.5$. Samples were treated with $750 \mu \mathrm{ls}$ of DMS for 10 mins at $24^{\circ} \mathrm{C}$ or 4 mins at $30^{\circ} \mathrm{C}$. Untreated controls were grown similarly but without DMS. Isoamyl alcohol/Betamercaptoethanol was added to both DMS treated and untreated samples and the RNA was extracted, DNase treated, and ribosomal RNA was removed using the Ribo-zero Gold rRNA removal kit (Illumina). Reverse transcription was done using the TGIRT-III (Ingex) enzyme with primers for TLC1 (DG365, DG351 and DG353), NME1 (DG355), or ASH1 (DG357) RNAs (See supplementary Table 3 for sequences of primers). After reverse transcription the RNA:DNA hybrids were incubated with RNase $\mathrm{H}$ to release the cDNA products as previously described ${ }^{36}$.

The cDNA was then used as a template to add adapters by PCR using iProof $\mathrm{HF}$ Polymerase (BIO-RAD) with tiled primers for TLC1 DG348 + DG365, DG364 + DG351, DG352 + DG353; NME DG354 + DG355 (Supplementary Table 3). Each $\mathrm{PCR}$ reaction was done separately and pooled together for sequencing at a final sample concentration of $1 \mathrm{ng} / \mu \mathrm{l}$. The libraries were then prepared from the pooled samples and sequenced using the HiSeq Rapid Cluster Kit v2 (Illumina) and HiSeq 
( $2 \times 180$ nt, 180 cycles per end) at the Princeton University core facility. Datasets generated for DMS-MaPseq are available through http://www.ncbi.nlm.nih.gov/ bioproject/548768.

Analysis of DMS-MaPseq data. Illumina sequence data were split by sample with dual barcodes using barcode splitter ${ }^{58}$, allowing 1 mismatch per barcode. Each sample was amplicon-split using an in-house script (split_amplicons.tcsh). Adapters were trimmed with cutadapt (Galaxy version 1.16) ${ }^{59}$, and forward and reverse reads were merged using FLASH (galaxy version 1.2.11.3) ) $^{59}$ with \pm 10 bp overlap. Reads were checked for quality using FastQC (galaxy version 0.71$)^{60}$. Pairs that did not merge were discarded. Merged reads were then mapped using BWA-MEM (Galaxy version 0.7.1.7.1 $)^{61,62}$ with default options. Mutations were identified using an in-house FreeBayes script (version v1.2.0-2-g29c4002; freebayes div and conq. $\mathrm{tcsh})^{63}$. DMS reactivities and local coverages were then calculated using an inhouse script (count_snps.tcsh). Finally, unique amplicon abundances were calculated using mergeSeqs.pl (version 2.8 - a part of the CFF suite) ${ }^{64}$. All analysis steps were initiated via either galaxy workflow or batchCommander (version 3.12).

DMS reactivities were calculated from mutation counts and local coverages in the treated and untreated samples as follows. Let $X_{k}$ and $C_{k}$ denote the mutation count and coverage at nucleotide $k$, respectively. Using superscripts ' + ' and '-' for the treated and untreated samples, respectively, we computed the reactivity at $k$ as previously described ${ }^{39}$

$$
r_{k}=\max \left(\frac{\frac{X_{k}^{+}}{C_{k}^{+}}-\frac{X_{k}^{-}}{C_{k}^{-}}}{1-\frac{X_{k}^{-}}{C_{k}^{-}}}, 0\right)
$$

Reactivities were normalized using the $2-8 \%$ approach after masking the reactivities for guanines and uracils (Low and Weeks, 2010). Next, we used dStruct to perform differential analysis on the normalized reactivities ${ }^{41}$.

We compared WT to pop 1 at $24^{\circ} \mathrm{C}$, WT to pop6 at $24^{\circ} \mathrm{C}$, WT to pop 1 at $30^{\circ} \mathrm{C}$ and WT to pop 6 at $30^{\circ} \mathrm{C}$ for the ASH1, NME1 and TLC1 RNAs. We searched for differential regions that were at least 5 nts in length, with $P$-value $<0.05$ and False discovery rate-adjusted $P$-value ( $q$-value) $<0.1$. The FDR control was done separately for each pairwise comparison of conditions. In addition, we ensured a minimum effect size by requiring mean $\Delta d>0.01$ for these regions, where $\Delta d$ is the difference between within-strain and between-strain dissimilarity scores per nucleotide. It quantifies the degree to which the variation between strains surpasses that of biological replicates for each strain.

TMG immunoprecipitation. Immunoprecipitations were done as previously described ${ }^{65}$ with some modifications. Briefly, $60 \mu \mathrm{g}$ of total RNA were incubated with Anti-2,2,7-Trimethylguanosine Mouse mAb (K121) Agarose Conjugate (Millipore) over-night at $4^{\circ} \mathrm{C}$, followed by five washes with NET-2 buffer ( $150 \mathrm{mM} \mathrm{NaCl}, 0.05 \% \mathrm{NP}-40,50 \mathrm{mM}$ Tris- $\mathrm{HCl}, \mathrm{pH}$ 7.4) The immunoprecipitates were DNase treated with Turbo DNA-free and analyzed by RT-qPCR as specified above. TLC1 levels were measured using primers DG293 and DG294 for TLC1 and DG52 and DG53 for ACT1 (see Supplementary table 3 for sequences). Data were quantified by IP/Input and normalized to levels of ACT1 mRNA.

3' RACE. To determine the sequences of the $3^{\prime}$ ends of TLC1 RNA in WT and pop cells, we performed $3^{\prime}$ RACE as previously described ${ }^{66}$ with some modifications. Briefly, cells were grown in YC media to $\mathrm{OD}_{600}=0.5$ at $24^{\circ} \mathrm{C}$ and $30^{\circ} \mathrm{C}$ and RNA was extracted as described above. Total RNA $(5 \mu \mathrm{g})$ was DNase treated (Invitrogen AM107) as described above and ribosomal RNA was depleted with Ribo-zero Gold rRNA removal kit (Illumina). The RNA was concentrated using RNA clean and concentrator columns (Ribo-zero) and eluted in $11 \mu \mathrm{ls}$ of RNase-free water. Then, $600 \mathrm{ng}$ of rRNA-depleted RNA was ligated to $5 \mu \mathrm{M}$ of Universal miRNA Cloning Linker (New England BioLabs) for $24 \mathrm{~h}$ at $25^{\circ} \mathrm{C}$. After RNA clean up with RNA clean and concentrator-5 (Zymo research), the cDNA was synthesized using 5 pmol of universal RT primer (UP1) with SuperScript III reverse transcriptase (Invitrogen). PCR amplification was carried out using $2 \mu \mathrm{ls}$ of cDNA, $5 \mu \mathrm{M}$ of the RT universal primer and TLC1 internal primer DG389 (see Supplementary Table 3 for sequences) with iProof HF Supermix (Bio-Rad). $3 \mu \mathrm{ls}$ of PCR products were analyzed on a $2.5 \%$ agarose gel to visualize TLC1 transcripts followed by Select-asize DNA Clean and concentrator (Zymo-research) to retain products $\leq 600 \mathrm{nt}$. The amplicon samples were quantified using Qubit 2.0 Fluorometer (Life Technologies, Carlsbad, CA, USA) and the DNA integrity was checked using Agilent TapeStation (Agilent Technologies, Palo Alto, CA, USA).

3' RACE DNA library preparation and illumina sequencing. DNA library preparations, sequencing reactions, and initial bioinformatics analysis were conducted at GENEWIZ (South Plainfield, NJ, USA). DNA library preparation, clustering, and sequencing reagents were used throughout the process using NEBNext Ultra DNA Library Prep kit following the manufacturer's recommendations (Illumina, San Diego, CA, USA). Adapter-ligated DNA was indexed and enriched by limited cycle PCR. DNA libraries were validated using a DNA 1000 Chip on the Agilent 2100 Bioanalyzer (Agilent Technologies, Palo Alto, CA, USA), and quantified by
Qubit and real time PCR (Applied Biosystems, Carlsbad, CA, USA). The DNA libraries multiplexed in equal molar mass were loaded on the Illumina MiSeq instrument according to manufacturer's instructions. The samples were sequenced using a $2 \times 250$ paired-end (PE) configuration. Image analysis and base calling were conducted by the MiSeq Control Software (MCS) on the Illumina MiSeq instrument. $3^{\prime}$ RACE data is available through https://www.ncbi.nlm.nih.gov/sra/ PRJNA548560

3' RACE data analysis. The raw Illumina reads were checked for sequencing adapters and quality via FastQC. The reads were trimmed of their sequencing adapters and nucleotides with poor quality using Trimmomatic v. 0.36. Raw sequence data (.bcl files) generated from Illumina MiSeq were converted into fastq files and de-multiplexed using Illumina bsl2fastq v. 2.17 program. The paired reads were merged (FLASH-Galaxy 1.2.11.3) and mapped (BWA-MEM-Galaxy 0.7.1.7.1) as described above. The $5^{\prime}$ and $3^{\prime}$ end adapters were trimmed with Cutadapt (Galaxy version 1.16) and the sequences abundances were computed using a custom Galaxy workflow (Mature_RNA_Abundance_Analysis_Helper_1_ (calc_abund_all)).

RNA FISH. Two 50-nt DNA probes were generated (Fig. 9a), one for TLC1 and one for ITS1, an internal segment of the $35 \mathrm{~s}$ rRNA precursor RNA that is removed in the nucleolus. The TLC1 probe (GW1), which targeted a 26 nt region of TLC1, was labeled with Cy3 (green) at its $5^{\prime}$ end, and the ITS1 probe (GW3), which targeted a $30 \mathrm{nt}$ region of ITS1 RNA, was labeled with Cy5 (red) at its $5^{\prime}$ end. Both probes were designed to adopt a hairpin structure with a 10-nt overhang according to $\mathrm{mFOLD}^{67}$ (see Supplementary Table 3 for sequences of probes). Unlabeled control probes targeted nucleotides 389-414 on the TLC1 transcript (GW2) or nucleotides 70-99 in ITS1 (GW4). Probes were reconstituted in TE buffer and subjected to an annealing cycle with denaturation at $95^{\circ} \mathrm{C}$ and annealing at $55^{\circ} \mathrm{C}$ in one-minute steps for 30 cycles. Cells were grown overnight in $150 \mathrm{~mL}$ of SD. Complete or SD -ura media at either $24^{\circ} \mathrm{C}$ or $30^{\circ} \mathrm{C}$ to an $\mathrm{OD}_{600}$ of 0.6. Cells were prepared for FISH as described previously ${ }^{47}$ with a few modifications. Cells were fixed in $10 \% \mathrm{~V} / \mathrm{V}$ formaldehyde at room temperature for $45 \mathrm{~min}$ and spheroplasted and permeabilized overnight in ethanol. Hybridization was performed overnight at $30^{\circ} \mathrm{C}$ with $50 \mathrm{nM}$ FISH probes in a buffer containing $10 \% \mathrm{~W} / \mathrm{V}$ dextran sulfate, $2 \mathrm{mM}$ vanadyl ribonucleoside complex, 2X SSC, $0.001 \% \mathrm{~W} / \mathrm{V}$ E.Coli tRNA, $0.3 \mu \mathrm{M}$ bovine serum albumin, RNase free water, and $10 \% \mathrm{~V} / \mathrm{V}$ formamide. Cells were pelleted, resuspended in $1 \mathrm{~mL}$ of wash buffer containing $2 \mathrm{X} \mathrm{SSC}, 10 \% \mathrm{~V} / \mathrm{V}$ formamide, RNase free water, and $1 \mu \mathrm{L}$ of $1 \mathrm{mg} / \mathrm{mL}$ DAPI, and incubated for 10 minutes at $30^{\circ} \mathrm{C}$ to wash out weakly-bound probes. Cells were washed once more without incubation and then aspirated and kept at $4{ }^{\circ} \mathrm{C}$ until imaged. $3 \mu \mathrm{L}$ of concentrated cells were applied to a slide pre-cleaned with ethanol and mixed by gentle pipetting with $3 \mu \mathrm{L}$ of oxygen scavenging buffer containing $10 \mathrm{mM}$ Tris at $\mathrm{pH} 8,2 \mathrm{X} \mathrm{SSC}, 2.5 \mathrm{mM}$ protocatechuic acid (PCA), $10 \mathrm{Nm}$ protocatechuate-3,4-dioxygenase (PCD) and $1 \mathrm{mM}$ 6-hydroxy-2,5,7,8-tetramethylchroman-2-carboxylic acid (Trolox). Slides were sealed with epoxy. Z-stack images were acquired at $100 \mathrm{~ms}$ exposure by Micromanager ${ }^{68}$, in $200 \mathrm{~nm}$ steps over $10 \mu \mathrm{m}$ using a motorized stage. Laser output was set to produce $25 \mathrm{~mW}$ of power at the sample plane for both $640 \mathrm{~nm}$ and $532 \mathrm{~nm}$ illumination (1185055, Coherent; LCX-532L-100, Oxxius), and the LED controller was set to $0.5 \mathrm{~V}$ for UV illumination (M375L4, Thorlabs). The laser light was spun by a $2 \mathrm{D}$-galvo system to achieve a uniform illumination ${ }^{69}$. Cell segmentation and FISH spot identification were performed using Matlab image processing toolbox. Nucleolus and nucleus locations were determined by intensity-based thresholding. Objects of volume smaller than 10 pixels were removed from the analysis. Spot location was extracted by applying a CLEAN algorithm ${ }^{70}$. In this algorithm, a Gaussian profile fit to a maximum intensity spot is sequentially subtracted from the original image until the intensity in the cell falls below the minimum acceptable intensity of a single fluorophore.

Reporting summary. Further information on research design is available in the Nature Research Reporting Summary linked to this article.

\section{Data availability}

The $3^{\prime}$ RACE and DMS-MaPseq datasets generated and analyzed during the current study are available in the PRJNA548560 and PRJNA548768 repositories, respectively. The source data underlying Figs. 2c-g, 4a-f, 5a-d, 6c-d, 7, 8a, d, 9b-c and Supplementary Figs. 3-6 and 8-13 are provided as a Source Data file. All data is available from the corresponding author upon reasonable request.

\section{Code availability}

Software for the analysis of $3^{\prime}$ RACE and DMS-MaPseq data is available at https://github com/hepcat72/RNAseP-MRP/ and described in Methods

Received: 31 May 2019; Accepted: 27 March 2020; Published online: 01 May 2020 


\section{References}

1. Vasianovich, Y. \& Wellinger, R. J. Life and death of yeast telomerase RNA. J. Mol. Biol. 429, 3242-3254 (2017).

2. Taggart, A. K. P., Teng, S.-C. \& Zakian, V. A. Estlp as a cell cycle-regulated activator of telomere-bound telomerase. Science 297, 1023-1026 (2002).

3. Fisher, T. S., Taggart, A. K. P. \& Zakian, V. A. Cell cycle-dependent regulation of yeast telomerase by Ku. Nat. Struct. Mol. Biol. 11, 1198-1205 (2004).

4. Tuzon, C. T., Wu, Y., Chan, A. \& Zakian, V. A. The saccharomyces cerevisiae telomerase subunit Est3 binds telomeres in a cell cycle- and Est1dependent manner and interacts directly with Est1 in vitro. PLoS Genet. 7, 1-12 (2011).

5. Lin, K.-W. W. et al. Proteomics of yeast telomerase identified Cdc48-Npl4Ufd1 and Ufd4 as regulators of Est1 and telomere length. Nat. Commun. 6 , 8290 (2015).

6. Osterhage, J. L., Talley, J. M. \& Friedman, K. L. Proteasome-dependent degradation of Estlp regulates the cell cycle-restricted assembly of telomerase in Saccharomyces cerevisiae. Nat. Struct. Mol. Biol. 13, 720-728 (2006).

7. Wu, Y. \& Zakian, V. A. The telomeric Cdc13 protein interacts directly with the telomerase subunit Est1 to bring it to telomeric DNA ends in vitro. Proc. Natl. Acad. Sci. USA 108, 20362-20369 (2011).

8. Mozdy, A. D. \& Cech, T. R. Low abundance of telomerase in yeast: implications for telomerase haploinsufficiency. RNA 12, 1721-1737 (2006).

9. Singer, M. S. \& Gottschling, D. E. TLC1: template RNA component of Saccharomyces cerevisiae telomerase. Science 266, 404-409 (1994).

10. Chapon, C., Cech, T. R. \& Zaug, A. J. Polyadenylation of telomerase RNA in budding yeast. RNA 3, 1337-1351 (1997).

11. Seto, aG., Zaug, aJ., Sobel, S. G., Wolin, S. L. \& Cech, T. R. Saccharomyces cerevisiae telomerase is an Sm small nuclear ribonucleoprotein particle. Nature 401, 177-180 (1999).

12. Bosoy, D., Peng, Y., Mian, I. S. \& Lue, N. F. Conserved N-terminal motifs of telomerase reverse transcriptase required for ribonucleoprotein assembly in vivo. J. Biol. Chem. 278, 3882-3890 (2003).

13. Gallardo, F., Olivier, C., Dandjinou, A. T., Wellinger, R. J. \& Chartrand, P. TLC1 RNA nucleo-cytoplasmic trafficking links telomerase biogenesis to its recruitment to telomeres. EMBO J. 27, 748-757 (2008)

14. Ferrezuelo, F., Steiner, B., Aldea, M. \& Futcher, B. Biogenesis of yeast telomerase depends on the importin mtr10. Mol. Cell. Biol. 22, 6046-6055 (2002).

15. Wu, H., Becker, D. \& Krebber, H. Telomerase RNA TLC1 shuttling to the cytoplasm requires mRNA export factors and is important for telomere maintenance. Cell Rep. 8, 1630-1638 (2014).

16. Peterson, S. E. et al. The function of a stem-loop in telomerase RNA is linked to the DNA repair protein Ku. Nat. Genet. 27, 64-67 (2001).

17. Hass, E. P. \& Zappulla, D. C. The Ku subunit of telomerase binds Sir4 to recruit telomerase to lengthen telomeres in S. cerevisiae. Elife 4, 1-19 (2015).

18. Chen, H. et al. Structural insights into yeast telomerase recruitment to telomeres. Cell 172, 331-343.e13 (2018).

19. Sabourin, M., Tuzon, C. T. \& Zakian, V. A. Telomerase and Tel1p preferentially associate with short telomeres in S. cerevisiae. Mol. Cell 27, 550-561 (2007).

20. Gallardo, F. et al. Live cell imaging of telomerase RNA dynamics reveals cell cycle-dependent clustering of telomerase at elongating telomeres. Mol. Cell 44, 819-827 (2011).

21. Pennock, E., Buckley, K. \& Lundblad, V. Cdc13 delivers separate complexes to the telomere for end protection and replication. Cell 104, 387-396 (2001).

22. Lemieux, B. et al. Active yeast telomerase shares subunits with ribonucleoproteins RNase P and RNase MRP. Cell 165, 1171-1181 (2016).

23. Esakova, O. \& Krasilnikov, A. S. Of proteins and RNA: the RNase P/MRP family. RNA 16, 1725-1747 (2010).

24. Fagerlund, R. D., Perederina, A., Berezin, I. \& Krasilnikov, A. S. Footprinting analysis of interactions between the largest eukaryotic RNase P/MRP protein Pop1 and RNase P/MRP RNA components. RNA 21, 1591-1605 (2015).

25. Lindahl, L., Fretz, S., Epps, N. \& Zengel, J. M. Functional equivalence of hairpins in the RNA subunits of RNase MRP and RNase P in Saccharomyces cerevisiae. RNA 6, 653-658 (2000)

26. Costanzo, M. et al. A global genetic interaction network maps a wiring diagram of cellular function. Science 353, aaf1420-1-14 (2016).

27. Perederina, A., Esakova, O., Koc, H., Schmitt, M. E. \& Krasilnikov, A. S. Specific binding of a Pop6/Pop7 heterodimer to the P3 stem of the yeast RNase MRP and RNase P RNAs. RNA 13, 1648-1655 (2007).

28. Lygerou, Z. et al. The POP1 gene encodes a protein component common to the RNase MRP and RNase P ribonucleoproteins. Genes Dev. 8, 1423-1433 (1994).

29. Vodenicharov, M. D. \& Wellinger, R. J. The cell division cycle puts up with unprotected telomeres: Cell cycle regulated telomere uncapping as a means to achieve telomere homeostasis. Cell Cycle 6, 1161-1167 (2007).

30. Bonetti, D. et al. Shelterin-like proteins and Yku inhibit nucleolytic processing of Saccharomyces cerevisiae telomeres. PLoS Genet. 6, 1 (2010).
31. Franke, J., Gehlen, J. \& Ehrenhofer-Murray, A. E. Hypermethylation of yeast telomerase RNA by the snRNA and snoRNA methyltransferase Tgs1. J. Cell Sci. 121, 3553-3560 (2008).

32. Noël, J. F., Larose, S., Elela, S. A. \& Wellinger, R. J. Budding yeast telomerase RNA transcription termination is dictated by the Nrd1/Nab3 non-coding RNA termination pathway. Nucleic Acids Res. 40, 5625-5636 (2012).

33. Steinmetz, E. J., Conrad, N. K., Brow, D. A. \& Corden, J. L. RNA-binding protein Nrd1 directs poly(A)-independent $3^{\prime}$-end formation of RNA polymerase II transcripts. Nature 413, 327-331 (2001)

34. Perederina, A., Berezin, I. \& Krasilnikov, A. S. In vitro reconstitution and analysis of eukaryotic RNase P RNPs. Nucleic Acids Res. 46, 6857-6868 (2018).

35. Strobel, E. J., Yu, A. M. \& Lucks, J. B. High-throughput determination of RNA structures. Nat. Rev. Genet. (2018). https://doi.org/10.1038/s41576-018-0034-x

36. Zubradt, M. et al. DMS-MaPseq for genome-wide or targeted RNA structure probing in vivo. Nat. Methods 14, 75-82 (2016).

37. Wells, S. E., Hughes, J. M., Haller Igel, A. \& Ares, M. Jr. Use of dimethyl sulfate to probe RNA structure in vivo. Methods Enzymol. 318, 479-493 (2000).

38. Mohr, S. et al. Thermostable group II intron reverse transcriptase fusion proteins and their use in cDNA synthesis and next-generation RNA sequencing. RNA 19, 958-970 (2013).

39. Aviran, S., Lucks, J. B. \& Pachter, L. RNA structure characterization from chemical mapping experiments. In 49th Annual Allerton Conference on Communication, Control, and Computing. 1743-1750 (IEEE, USA, 2011). https://doi.org/10.1109/Allerton.2011.6120379

40. Li, H. \& Aviran, S. Statistical modeling of RNA structure profiling experiments enables parsimonious reconstruction of structure landscapes. Nat. Commun. 9, 606 (2018).

41. Choudhary, K., Lai, Y.-H., Tran, E. J. \& Aviran, S. dStruct: identifying differentially reactive regions from RNA structurome profiling data. Genome Biol. 20, 1-26 (2019).

42. San Paolo, S. et al. Distinct roles of non-canonical poly(A) polymerases in RNA metabolism. PLoS Genet. 5, 13-17 (2009).

43. Choi, H. M. T., Beck, V. A. \& Pierce, N. A. Next-generation in situ hybridization chain reaction: higher gain, lower cost, greater durability. ACS Nano 8, 4284-4294 (2014).

44. Broadwater, D. W. B. \& Kim, H. D. The effect of basepair mismatch on DNA strand displacement. Biophys. J. 110, 1476-1484 (2016).

45. Ouenzar, F. et al. Cell cycle-dependent spatial segregation of telomerase from sites of DNA damage. J. Cell Biol. 216, 2355-2371 (2017).

46. Laterreur, N., Eschbach, S. H. S. H., Lafontaine, D. A. \& Wellinger, R. J. A new telomerase RNA element that is critical for telomere elongation. Nucleic Acids Res. 41, 7713-7724 (2013).

47. Wadsworth, G. M., Parikh, R. Y., Choy, J. S. \& Kim, H. D. mRNA detection in budding yeast with single fluorophores. Nucleic Acids Res. 45, e141 1-9 (2017).

48. Wilusz, J. E., Freier, S. M. \& Spector, D. L. $3^{\prime}$ end processing of a long nuclearretained noncoding RNA yields a tRNA-like cytoplasmic RNA. Cell 135, 919-932 (2008)

49. Lingner, J., Cech, T. R., Hughes, T. R. \& Lundblad, V. Three ever shorter telomere (EST) genes are dispensable for in vitro yeast telomerase activity. Proc. Natl. Acad. Sci. USA 94, 11190-11195 (1997).

50. Mcdonald, K. R. Proteomic Investigation of Protein Interactions and Post Translational Modifications of the Pfh1 Helicase and Yeast Telomerase Holoenzymes. (Princeton University, 2012).

51. Gietz, R. D. \& Schiestl, R. H. Large-scale high-efficiency yeast transformation using the LiAc/SS carrier DNA/PEG method. Nat. Protoc. 2, 38-41 (2007)

52. Longtine, M. S. et al. Additional modules for versatile and economical PCRbased gene deletion and modification in Saccharomyces cerevisiae. Yeast 14, 953-961 (1998).

53. Sabourin, M., Tuzon, C. T., Fisher, T. S. \& Zakian, V. A. A flexible protein linker improves the function of epitope-tagged proteins inSaccharomyces cerevisiae. Yeast 24, 39-45 (2007).

54. Runge, K. W. \& Zakian, V. A. Introduction of extra telomeric DNA sequences into Saccharomyces cerevisiae results in telomere elongation. Mol. Cell. Biol. 9 1488-1497 (1989)

55. Keogh, M.-C., Cho, E.-J., Podolny, V. \& Buratowski, S. Kin28 is found within TFIIH and a Kin28-Ccl1-Tfb3 trimer complex with differential sensitivities to T-Loop phosphorylation. Mol. Cell. Biol. 22, 1288-1297 (2002).

56. Livak, K. J. \& Schmittgen, T. D. Analysis of relative gene expression data using real-time quantitative PCR and the 2(-Delta Delta C(T)) Method. Methods 25, 402-408 (2001).

57. Azvolinsky, A., Giresi, P. G., Lieb, J. D. \& Zakian, V. Highly transcribed RNA polymerase II genes are impediments to replication fork progression in Saccharomyces cerevisiae. Mol. Cell 34, 722-734 (2009).

58. Parsons, L. and Leach, R. Barcode Splitter (2019). https://doi.org/10.5281/ zenodo. 2566616 
59. Magoč, T. \& Salzberg, S. L. FLASH: fast length adjustment of short reads to improve genome assemblies. Bioinformatics 27, 2957-2963 (2011).

60. Andrews, S. FastQC A Quality Control tool for High Throughput Sequence Data (2018).

61. Li, H. Aligning sequence reads, clone sequences and assembly contigs with BWA-MEM. arXiv [q-bio.GN] (2013).

62. Li, H. \& Durbin, R. Fast and accurate long-read alignment with BurrowsWheeler transform. Bioinformatics 26, 589-595 (2010).

63. Garrison, E. \& Marth, G. Haplotype-based variant detection from short-read sequencing 1-9 (2012).

64. Tikhonov, M., Leach, R. W. \& Wingreen, N. S. Interpreting 16S metagenomic data without clustering to achieve sub-OTU resolution. ISME J. 9, 68-80 (2015).

65. Hayes, K. E., Barr, J. A., Xie, M., Steitz, J. A. \& Martinez, I. Immunoprecipitation of tri-methylated capped RNA. Bio. Protoc. 8, e2717 1-13 (2018).

66. Moon, D. H. et al. Poly(A)-specific ribonuclease (PARN) mediates $3^{\prime}$-end maturation of the telomerase RNA component. Nat. Genet. 47, 1482-1488 (2015).

67. Zuker, M. Mfold web server for nucleic acid folding and hybridization prediction. Nucleic Acids Res. 31, 3406-3415 (2003).

68. Edelstein, A., Amodaj, N., Hoover, K., Vale, R. \& Stuurman, N. Computer control of microscopes using $\mu$ Manager. Curr. Protoc. Mol. Biol. Chapter 14, Unit14.20 (2010).

69. Ellefsen, K. L., Dynes, J. L. \& Parker, I. Spinning-spot shadowless TIRF microscopy. PLoS ONE 10, e0136055 (2015).

70. Högbom, J. A. Aperture synthesis with a non-regular distribution of interferometer baselines. Astron. Astrophys. Suppl. 15, 417 (1974).

\section{Acknowledgements}

We thank C. Boone and M. Costanzo for pop strains, J. Lucks for advice on structural analysis, S. Rouskin for advice on DMS-MaPseq, C. DeCoste and the Princeton Molecular Biology FACS facility for help with FACS and W. Wang and the Genomics Core Facility for help with sequencing. We thank C. Greider for suggesting the experiment on Yku titration. We are particularly grateful to A. Korennykh for his careful reading of the manuscript and his many valuable suggestions on the DMS protection experiments and their interpretation. Work in the Zakian lab is supported by 1R35GM118279 from the NIH. GMW and HDK acknowledge support from Georgia Institute of Technology startup funds and NIH grant R01-GM112882.

\section{Author contributions}

Overall design and interpretation of experiments were done by P.D.G. and V.A.Z. R.W.L. processed deep sequencing data and designed code for the analysis of $3^{\prime}$ RACE and
DMS-MaPseq. P.D.G. conducted all of the experiments except the localization of TLC1 in Fig. 9, which was conducted by G.M.W. with the guidance of H.K. G.M.W. also developed a custom analysis code for FISH localization. K.C. and S.A. performed differential reactivity analysis of the DMS-MaPseq. H.L. contributed to determining methods for analyzing the DMS-MaPseq data. P.D.G. and V.A.Z. wrote the paper with contributions from all authors.

\section{Conflict of interest}

The authors declare no conflict of interest.

\section{Additional information}

Supplementary information is available for this paper at https://doi.org/10.1038/s41467020-15875-9.

Correspondence and requests for materials should be addressed to V.A.Z.

Peer review information Nature Communications thanks Kazumori Tomita and the other, anonymous, reviewer(s) for their contribution to the peer review of this work. Peer reviewer reports are available.

Reprints and permission information is available at http://www.nature.com/reprints

Publisher's note Springer Nature remains neutral with regard to jurisdictional claims in published maps and institutional affiliations.

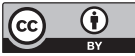

Open Access This article is licensed under a Creative Commons Attribution 4.0 International License, which permits use, sharing, adaptation, distribution and reproduction in any medium or format, as long as you give appropriate credit to the original author(s) and the source, provide a link to the Creative Commons license, and indicate if changes were made. The images or other third party material in this article are included in the article's Creative Commons license, unless indicated otherwise in a credit line to the material. If material is not included in the article's Creative Commons license and your intended use is not permitted by statutory regulation or exceeds the permitted use, you will need to obtain permission directly from the copyright holder. To view a copy of this license, visit http://creativecommons.org/ licenses/by/4.0/.

(C) The Author(s) 2020 